\title{
Bonobo nest site selection and the importance of predictor scales in primate ecology
}

\author{
Adeline Serckx ${ }^{1,2,3,4 *}$ | Marie-Claude Huynen ${ }^{1}$ | Roseline C. Beudels-Jamar ${ }^{2}$ | \\ Marie Vimond $^{1}$ | Jan Bogaert ${ }^{5}$ | Hjalmar S. Kühl ${ }^{4,6}$
}

${ }^{1}$ Primatology Research Group, Behavioral Biology Unit, University of Liege, Liege, Belgium

${ }^{2}$ Conservation Biology Unit, Royal Belgian Institute of Natural Sciences, Brussels, Belgium

${ }^{3}$ Ecole Régionale Post-Universitaire d'Aménagement et de Gestion Intégrés des Forêts et Territoires Tropicaux, Kinshasa, Democratic Republic of the Congo

${ }^{4}$ Department of Primatology, Max Planck Institute for Evolutionary Anthropology, Leipzig, Germany

${ }^{5}$ Biodiversity and Landscape Architecture Unit, Gembloux AgroBio-Tech, University of Liege, Gembloux, Belgium

${ }^{6}$ German Center for Integrative Biodiversity Research (iDiv), Leipzig, Germany

\section{${ }^{*}$ Correspondence}

Adeline Serckx, Primatology Research Group, Behavioral Biology Unit, University of Liege, Liege, Belgium.

Email: adelineserckx@gmail.com

\section{Funding Information}

This research was supported by National Fund for Scientific Research, Royal Belgian Institute of Natural Sciences and Ecole Régionale Postuniversitaire d'Aménagement et de Gestion Intégrés des Forêts et Territoires Tropicaux.
The role of spatial scale in ecological pattern formation such as the geographical distribution of species has been a major theme in research for decades. Much progress has been made on identifying spatial scales of habitat influence on species distribution. Generally, the effect of a predictor variable on a response is evaluated over multiple, discrete spatial scales to identify an optimal scale of influence. However, the idea to identify one optimal scale of predictor influence is misleading. Species-environment relationships across scales are usually sigmoid increasing or decreasing rather than humped-shaped, because environmental conditions are generally highly autocorrelated. Here, we use nest count data on bonobos (Pan paniscus) to build distribution models which simultaneously evaluate the influence of several predictors at multiple spatial scales. More specifically, we used forest structure, availability of fruit trees and terrestrial herbaceous vegetation (THV) to reflect environmental constraints on bonobo ranging, feeding and nesting behaviour, respectively. A large number of models fitted the data equally well and revealed sigmoidal shapes for bonobo-environment relationships across scales. The influence of forest structure increased with distance and became particularly important, when including a neighbourhood of at least $750 \mathrm{~m}$ around observation points; for fruit availability and THV, predictor influence decreased with increasing distance and was mainly influential below 600 and $300 \mathrm{~m}$, respectively. There was almost no difference in model fit, when weighing predictor values within the extraction neighbourhood by distance compared to simply taking the arithmetic mean of predictor values. The spatial scale models provide information on bonobo nesting preferences and are useful for the understanding of bonobo ecology and conservation, such as in the context of mitigating the impact of logging. The proposed approach is flexible and easily applicable to a wide range of species, response and predictor variables and over diverse spatial scales and ecological settings.

\section{KEYWORDS}

bonobo, nest count spatial scale, species distribution model, weighting functions

\section{1 | INTRODUCTION}

The role of spatial scale has been a major research theme in ecology for decades due to the significant contribution it has made to our understanding of biological patterns and processes (Levin, 1992; Marceau, 1999; Wheatley \& Johnson, 2009; Wiens, 1989). The current context of local to global landscape modification and habitat fragmentation makes this topic even more relevant (Riitters, Wickham, Neill, Jones, \& Smith, 2000). The dependence of species-environment relationships on spatial scales provides crucial insights into underlying processes, such as ranging and establishment of territories (Forester, Kyung Im, \& Rathouz, 2009; Johnson, Boyce, Mulders, \& Gunn, 2004a; Rhodes, McAlpine, Lunney, \& Possingham, 2005), foraging (Henry et al., 2012; Johnson et al., 2004b), feeding (Boyce, 2006; Mayor, Schaefer, Schneider, Mahoney, \& Mayor, 2007), sleeping and resting (Fischer \& Lindenmayer, 2006; Meyer \& Thuiller, 2006). It is also necessary for understanding the consequences of habitat change (Fischer \& Lindenmayer, 2006) and for suggesting valuable areas and 
management practices for conservation (Johnson, Seip, \& Boyce, 2004c; Nams, Mowat, Panian, 2006; Seo, Thorne, Hannah, \& Thuiller, 2009; Vaughan \& Ormerod, 2003).

In recent years, much conceptual and methodological progress has been made on how to identify appropriate spatial scales in speciesenvironment relationships (Mayor, Schneider, Schaefer, \& Mahoney, 2009; Urban, 2004; Wheatley, 2010). The structure of typical ecological information, including field (Anderson et al., 2005; Mayor et al., 2007; Rhodes, Mcalpine, Zuur, Smith, \& leno, 2009) and remotely-sensed data (Marceau \& Hay, 1999; Woodcock \& Strahler, 1987) gives researchers the opportunity to work at discrete scales, including different grains ('size of individual units of observation') and extents ('the overall area encompassed by a study') (Wiens, 1989). Various studies have used this information to study foraging behaviour in response to the spatial distribution and variation of food resources, the use of home ranges, the selection of sleeping and resting sites or the geographical distribution of populations. In elks, for example, predator avoidance defines their occurrence at larger spatial scales than habitat suitability (Anderson et al., 2005; Fortin, Beyer, Boyce, \& Smith, 2005). In Cross River gorillas, human impact explains their patchy distribution within areas of suitable habitat, whereas food availability is only important at smaller spatial scales (Imong, Robbins, Mundry, Bergl, \& Kühl, 2014a,b; Sawyer \& Brashares, 2013).

The exact scale over which environmental factors influence the distribution and behaviour of a species is, however, usually unknown. This often leads to an arbitrary choice of grain and extent being made when evaluating species-environment relationships [for a review see Wheatley and Johnson (2009)]. In order to overcome this problem, some authors have suggested to incorporate information on animal movement (Forester et al., 2009), such as home range behaviour (Rhodes et al., 2005) or niche partitioning between sympatric species (Pita, Mira, \& Beja, 2011) to approximate suitable scales. Whereas this is certainly a very useful approach for a number of species, required radio-telemetry data or other highly detailed information on how animals use their environment are not easily available for other species. This limits the applicability of such techniques for evaluating species-environment relationships.

Another proposed solution is to gather scale information from the existing literature. The influence of spatial scales, however, is not static, but varies according to the environmental and demographic context. Home range sizes have been shown to differ even within a population (Mule deer: Kie, Bowyer, Nicholson, Boroski, \& Loft, 2002; Nicholson, Bowyer, Kie, Journal, \& May, 1997; Moose: van Beest, Rivrud, Loe, Milner, \& Mysterud, 2011), core areas can vary over time (Grey-cheeked mangabey: Janmaat, Olupot, Chancellor, Arlet, \& Waser, 2009) and foraging behaviour can vary spatio-temporally (e.g. primates: Bowyer and Kie 2006; Boyer et al., 2006).

To overcome these limitations, several authors have suggested studying scale-dependent species-environment relationships by investigating a range of spatial scales instead of assuming one fixed and discrete scale only (Johnson et al., 2004b; Mayor et al., 2009; Nams et al., 2006; Wheatley, 2010). However, the evaluation of a suitable range of spatial scales for identifying those which best explain observed patterns requires a careful selection procedure to not violate fundamental statistical principles. Indeed, testing multiple predictors across a large number of spatial scales increases the probability of finding erroneously significant results. This is equivalent to a step-wise model selection procedure in which several variables are added and removed according to their significance to finally determine a best model. This procedure leads to greatly inflated Type I error rates (i.e. the probability of erroneously rejecting a true null hypothesis, (Forstmeier \& Schielzeth, 2011; Mundry \& Nunn, 2009; Whittingham, Stephens, Bradbury, \& Freckleton, 2006).

In addition, studies have shown that selecting one 'optimal' scale for environment variables is generally not appropriate when investigating species-environment relationships. This is because environmental factor can influence animal distribution and behaviour across a range of scales. It may also occur because environmental factors are frequently autocorrelated. As a consequence, many models will fit equally well in the range of the asymptotic part of the sigmoid species-environments relationships (Aue, Ekschmitt, Hotes, \& Wolters, 2012; Henry et al., 2012). This suggests to identify suitable spatial scale ranges with either minimum or maximum predictor influence rather than searching for an optimal scale. Aue et al. (2012) showed that including realistic distance weighting functions in a regression can solve this problem. It will naturally lead to a decrease in the influence of environmental predictors with distance and will produce sigmoid correlation curves that show saturation beyond a certain distance. These curves indicate suitable spatial scale ranges with minimum or maximum predictor influence. Such approach implies to deal with potentially large number of similarly well-fitting models, which requires a careful consideration of multiple testing issues and the development of appropriate techniques to draw inference.

Studies investigating spatial scale ranges of environmental predictors have remained scarce for primates. However, some studies have already shown the potential of evaluating spatial scales to gain insights into primate ecology, such as the impact of landscape spatial configuration on diet and behaviour of spider monkeys (OrdóñezGómez, Arroyo-Rodríguez, Nicasio-Arzeta, \& Cristóbal-Azkarate, 2015) or on distribution and abundance of howler monkeys (Anzures-Dadda \& Manson, 2007), the effect of habitat suitability on chimpanzee distribution (Torres et al., 2010), the influence of vegetation type, topography, tree characteristics and fruit availability on chimpanzee home range use for feeding and resulting nest distribution (Furuichi \& Hashimoto, 2004), human impact on gorilla distribution (Imong et al., 2014a; Sawyer \& Brashares, 2013) or gibbon habitat preference in fragmented landscapes (Gray, Phan, \& Long, 2010).

In this study, we examine how environmental factors influence bonobo nest site selection by investigating the spatial scale ranges of potential predictors. We hypothesise that environmental factors reflecting feeding behaviour (THV and fruit tree density, respectively) influence nest site selection at smaller spatial scales and 'forest structure', a factor characterising bonobo habitat, on the larger scale. We build distribution models to simultaneously evaluate the influence of several environmental predictors at multiple scales using survey data from a population living in western Democratic Republic of Congo. We show what investigating spatial scale ranges of 
environmental predictors can teach us about bonobo behaviour when direct observations are not possible. Finally, we discuss a possible way to define minimum and maximum spatial scales of predictor influence.

\section{2 | METHODS}

\section{1 | Study site}

The study site is located in the southern section of the Lake Tumba landscape (north of the Bateke Plateaux) in western Democratic Republic of Congo, close to the WWF research station of Malebo $\left(16.41-16.56^{\circ} \mathrm{E}, 2.45-2.66^{\circ} \mathrm{S}\right.$, Figure 1). This region can be characterised as a forest-savannah mosaic (Serckx et al., 2015). The altitude ranges from 300 to $700 \mathrm{~m}$ (Inogwabini, Bewa, Longwango, Abokome, \& Vuvu, 2008), and the mean daily temperature fluctuates around $25^{\circ} \mathrm{C}$ (Vancutsem et al., 2006). Annual rainfall oscillates around $1500-1600 \mathrm{~mm}$ and is interrupted by two dry seasons in February and July-August (Inogwabini et al., 2008). Forests mostly represent terra firma soil conditions and encompass various habitat types, i.e. recolonising Uapaca sp., old secondary, mixed mature, old growth monodominant, riverine gallery and Marantaceae forests (Inogwabini et al., 2008). The study site encompassed $170 \mathrm{~km}^{2}$, made up of $102 \mathrm{~km}^{2}$ of forest patches of various shapes and sizes connected to one another by a number of corridors. Surrounding savannahs were mainly herbaceous and partially used for cattle ranching. Human activities and settlements were concentrated in the west side of the study area. Six villages and 12 farms were directly adjacent to the forest and agriculture was located inside the forest. Two bonobo communities inhabit the forests, and have since 2007 been the subject of habituation and conservation programmes by WWF-DRC (Inogwabini et al., 2008).

\section{2 | Data collection}

From May to July 2011 and from Mid-March to -July 2012, we collected data on bonobo density, human activities and habitat types in the forests of the study site using standard line transect methodology

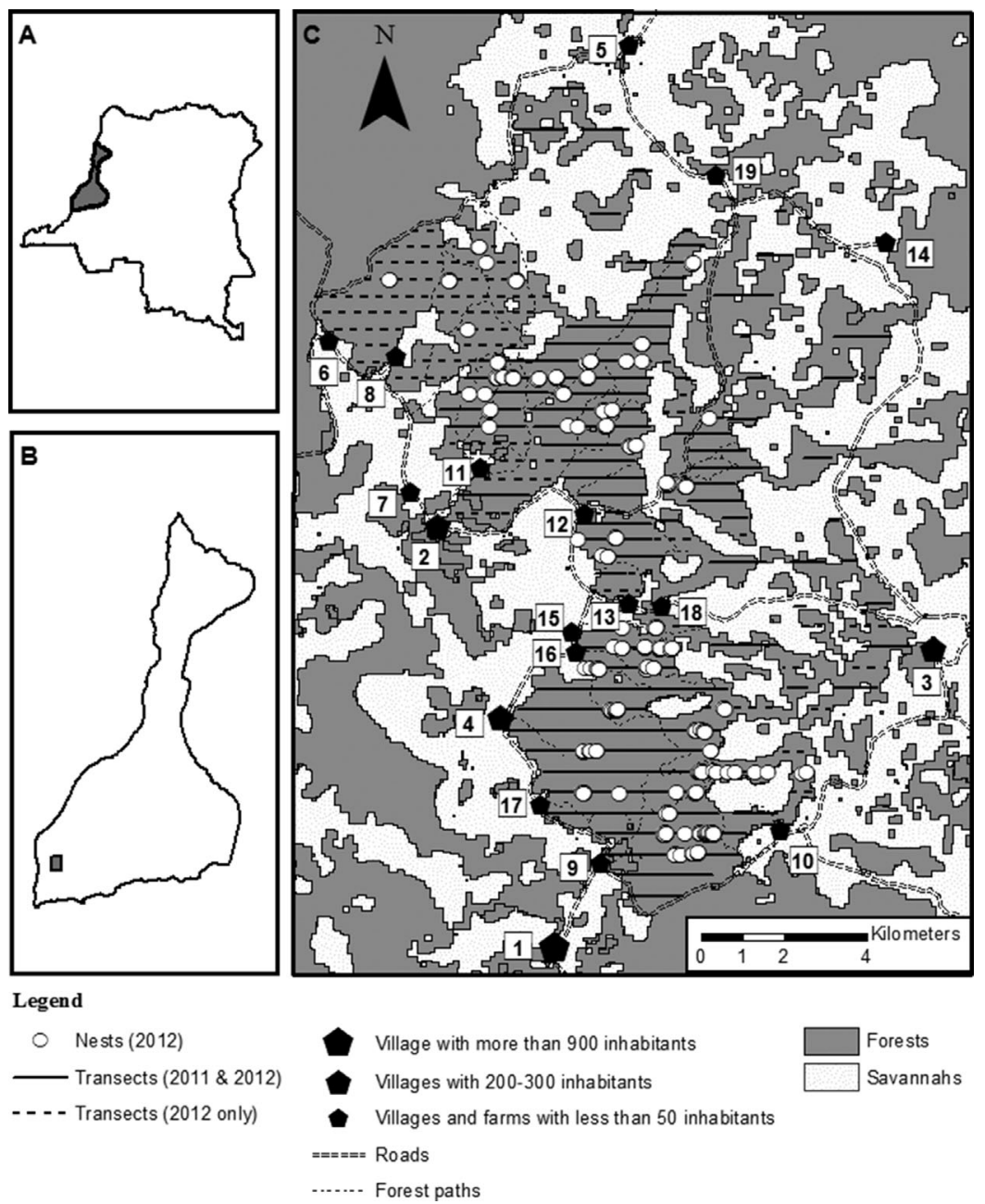

FIGURE 1 Map of the study site. A. Location of the Lake Tumba landscape in the Democratic Republic of Congo. B. Location of the study site within the Lake Tumba landscape. C. Map of the study site. Horizontal solid lines depict the line transects travelled in 2011 and 2012 , whereas the horizontal dashed lines indicate transects travelled only in 2012. Numbers next to villages correspond to the village names in Table 3A of Appendix 3. Number 19 represents the WWF-base 
(Buckland et al., 2001; Kuehl, Maisels, Ancrenaz, \& Williamson, 2008). We sampled 114 transects running from west to east, spaced $500 \mathrm{~m}$ apart and of variable lengths, with a total length of $179.1 \mathrm{~km}$ (Figure 1).

We systematically recorded information about the location of bonobo nests and their perpendicular distances from the line transects using a tape measure. We recorded all types of human hunting signs, i.e. cartridges, snares (whether made of wood, nylon thread or cable) and net-hunting signs. We recorded forest habitat-types according to the dominant understory-type and canopy tree-species. In order to categorise the dominant types of forest understory, we noted within $25 \mathrm{~m}$-segments one or two of the following categories (based on the classification in Reinartz, Inogwabini, Ngamankosi, \& Wema, 2006): open, liana, woody, Marantaceae or other terrestrial herbaceous vegetation (THV) (specifying the species of Marantaceae and THV, Appendix 1). For the canopy tree species we measured all trees with a DBH larger than $50 \mathrm{~cm}$ within a $10 \mathrm{~m}$ strip on both sides of the transects and recorded their scientific names (Appendix 2). Those large trees usually included the majority of fruiting trees which are found in a typical tropical forest in the Congo Basin (Bourland et al., 2012; Doucet, 2003; Madron \& Daumerie, 2004; Menga, Bayol, Nasi, \& Fayolle, 2012), and were further used to estimate an index of fruit treeavailability (see Section 2.3.3).

In order to complete our data set on human forest use, we travelled along roads and major forest paths, geo-referencing them and collecting socio-economic data in each of the villages and farms surrounding the study site. Between May and June 2012 we conducted a population census (Appendix 3). We interviewed 119 men on their hunting activities and practices (women do not hunt in the area); a total of 60 of these men answered that they regularly enter the forests for hunting. We asked these men about the frequency and location of their hunting activity in the forest, which they indicated on a map using the local names for each location in the forest (later called 'forest region'). This information was used to derive a variable on 'hunting pressure' (see Section 2.3.3).

\section{3 | Analytical methods}

\subsection{1 | General concept}

The principal idea of our study is to combine standard species distribution models based on generalised linear modelling (Araújo \& Guisan, 2006; Guisan \& Edwards, 2002; Guisan \& Zimmermann, 2000; Hedley \& Buckland, 2004; Murai et al., 2013; Wich et al., 2012) with a weighting function to account for the decreasing influence of environmental conditions with increasing distance from points of observation (Aue et al., 2012; Henry et al., 2012) (Figure 2). Based on the estimated model parameters, information can be then be derived about the range of the relevant spatial scale for each predictor. In the case of descending correlation curves this is a maximum and in the case of ascending correlation curves it is a minimum or distance from the point of observation, beyond or below which a predictor is much less influential. As hypothesised for our study, we would expect that predictors representing food availability would show decreasing correlation curves with increasing distance away from the points of observations and a maximum distance beyond which predictor influence is minimal. In contrast, habitat structure would be influential only beyond a minimum distance and would show an ascending correlation curve with increasing distance from the points of observation.

\subsection{2 | Response variable}

Bonobos, like all great apes, are elusive and observing them directly in their tropical forests habitat is usually nearly impossible. Because of this, researchers usually rely on counts of their sleeping nests to estimating their abundance (Kuehl et al., 2008; Plumptre, 2000). Bonobos build arboreal sleeping nests every night and, due to the long amount of time it takes them to decay, these nests accumulate within their home ranges as is the case for other great apes (Kouakou, Boesch, $\&$ Kuehl, 2011). For this reason, we used 'bonobo nest counts' as our response variable, summing all nests observed in 2012 on $500 \mathrm{~m}$-long transect segments $(N=411)$. We chose this segment length for several reasons. On the one hand, we needed segments to be long enough to avoid a highly skewed distribution of the response (i.e. a high proportion of segments with no observations and only a few segments with a large number of nests observed). On the other hand, the segment lengths needed to be small enough to allow us to evaluate local scale effects on bonobo nest distribution. Due to design constraints, segments located at the ends of transects were sometimes shorter than $500 \mathrm{~m}$.

\subsection{3 | Predictor variables}

We chose seven predictor variables to characterise the ecological and anthropogenic environment of the bonobo study population (Table 1). We first defined the predictor 'patch structure' to characterise forest structure at the study site, a forest-savannah mosaic. Bonobos are mainly a forest dwelling species, which is likely to be reflected in their ranging behaviour within this forest-savannah mosaic. We, therefore, expected this predictor to have an influence at larger scales. Bonobo mean daily foraging travel distance has been estimated as $2.6 \mathrm{~km}$ in dense forests (Furuichi et al., 2008). We first created a map of forests and savannahs in the study site, based on a non-supervised classification of a satellite image (Landsat7-2007-satellite imagery) with $50 \mathrm{~m}$ resolution (Appendix 4). From this map, we calculated the 'patch structure' by using a sliding window of 3 by 3 pixels and by summing, for the central pixel, the number of paired adjacent pixels classified as forest in each window (Riitters et al., 2000). We finally divided the number of paired adjacent pixels by the maximum number of paired adjacent pixels, i.e. 12 .

In order to quantify food availability within the forests, we defined two predictors representing the availability of (i) fruit trees and (ii) preferred terrestrial herbaceous vegetation (THV). Bonobos generally select food 'hot-spots' for sleeping (Serckx et al., 2014). We, therefore, expected both predictors to be relevant at small-scale ranges. The mean diameter of bonobo nesting sites in this study site is about $100 \mathrm{~m}$ (Serckx, unpublished data). For the index 'preferred THV', we calculated the proportion of THV species highly preferred as a food source by the bonobos (Malenky \& Stiles, 1991; Reinartz et al., 2006; Serckx, 2014): 


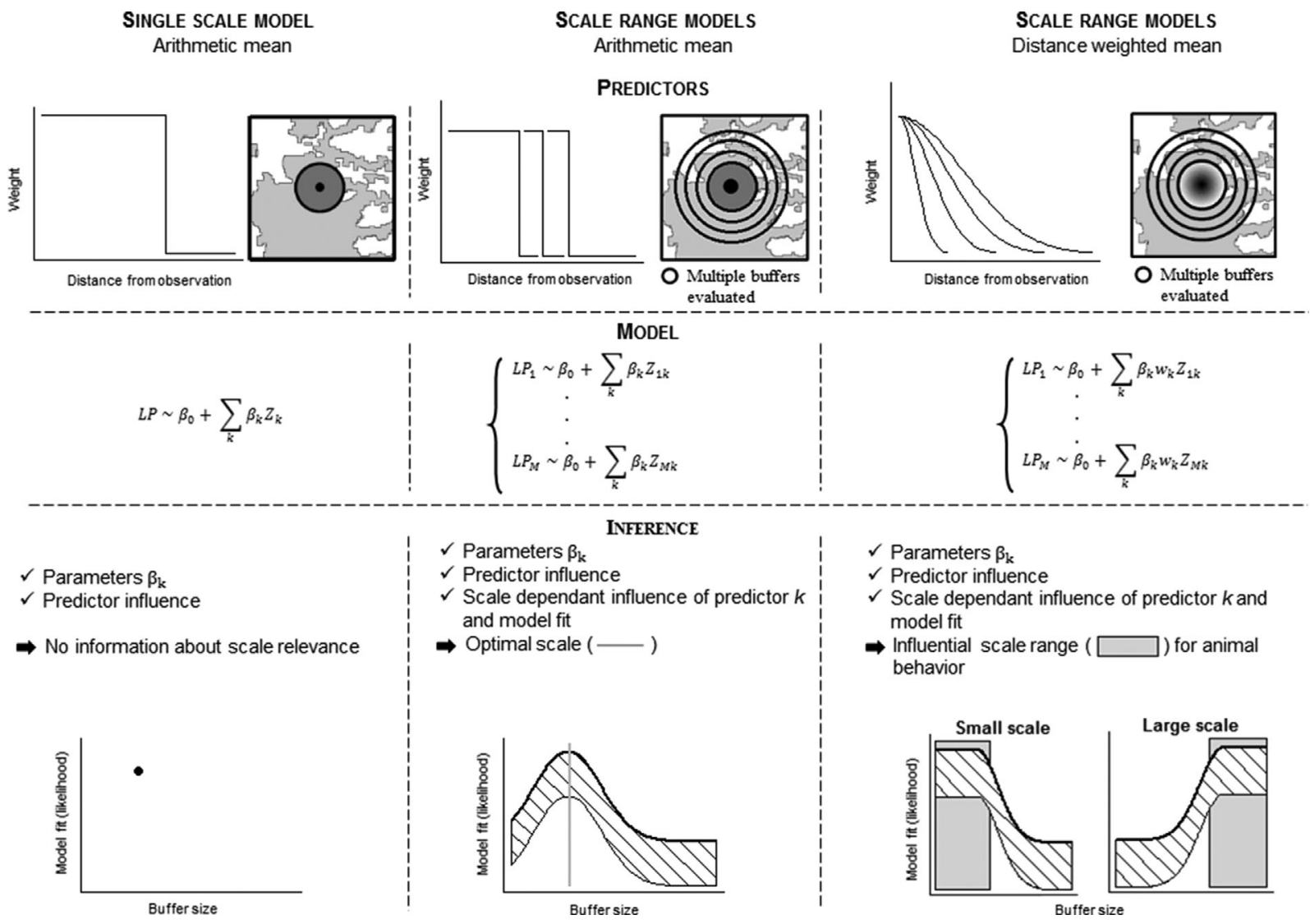

FIGURE 2 Principles of scale range species distribution models. Concepts of single and scale range spatial models differ with regard to predictor extraction, model-building and inference. The evaluation of a single spatial scale model with mean predictor values provides information on the spatial scale defined by expert opinion. In contrast, a set of spatial scale range models for predictors will provide a systematic assessment of predictor-response relationships across scales. The Akaike weight of each spatial scale is calculated in order to assess their relative importance and to identify the minimal or maximal spatial scale which we need to account for in order to represent the influence of the predictor on the response, if it exists (light grey boxes for models that contain distance weighting functions, light grey line for models with an arithmetic mean), and to draw inferences about these suitable spatial scale ranges. Because we simultaneously tested multiple scales using multiple predictors, the shaded polygons indicate the variation of model fit at each scale of a predictor, when we accounted for all tested spatial scales of the other predictors. For the scale range models with the weighted distance functions, the spatial pattern is representative for a predictor acting at a small spatial scale (an effect with a maximal requirement) and at a large scale (an effect with a minimal requirement)

two Marantaceae species, Haumania liebrechtsiana and Marantochloa leucantha, and Zingiberaceae species from the genus Aframomum on $25 \mathrm{~m}$-segments along transects. We then interpolated values across the study site with a resolution of $25 \mathrm{~m}$ by using the IDR function in ArcGIS 9.3 (with a power of 2 and a variable search radius). Next, we calculated an index of 'fleshy fruit availability'. Fruit species considered for this index were derived by selecting tree species (i) eaten by bonobos at different study sites (Beaune et al., 2013; Kano \& Mulavwa, 1992; Serckx, 2014) or (ii) producing fleshy fruits (Djoufack et al., 2007; Tailfer, 1989; Wilks \& Issembe, 2000). In order to estimate the canopy volume of trees, we used their basal area in square meters per hectare (Strier 1989, cited in Basabose, 2002) and calculated an index for $25 \mathrm{~m}$ segments along the transects by summing the basal area of all selected species on the segment. We then interpolated a map using the same method as we did for 'preferred THV'.

Next, as bonobos and other primates are known to show a high degree of site fidelity and often re-use nesting sites (Janmaat et al., 2009; Lehmann \& Boesch, 2003; Murray, Gilby, Mane, \& Pusey, 2008;
Stewart, Piel, \& McGrew, 2011), we incorporated the number of nests observed in the transect segment in 2011 as a 'nesting site fidelity' predictor. We expect this predictor to be an important one at small spatial scales, potentially accounting for nesting site characteristics and preferences not represented by other variables. As not all of the transects were sampled in 2011, we excluded the 127 transect segments for which this predictor was not available. We did not apply the distance weighting function for this predictor as the data did not cover the entire study site and an interpolation map would not be meaningful.

Finally, in order to control for human pressure, we used three variables representing different types of human influence. First, we summed the 'hunting signs' observed on each transect segment. We expected this predictor to influence bonobo density at small spatial scales of less than $10 \mathrm{~m}$ (Reinartz et al., 2006), as bonobos could easily avoid them. Second, we derived 'hunting pressure' from our questionnaire data by estimating a daily mean number of adults with the potential to enter a specific forest area (Appendix 4). The 


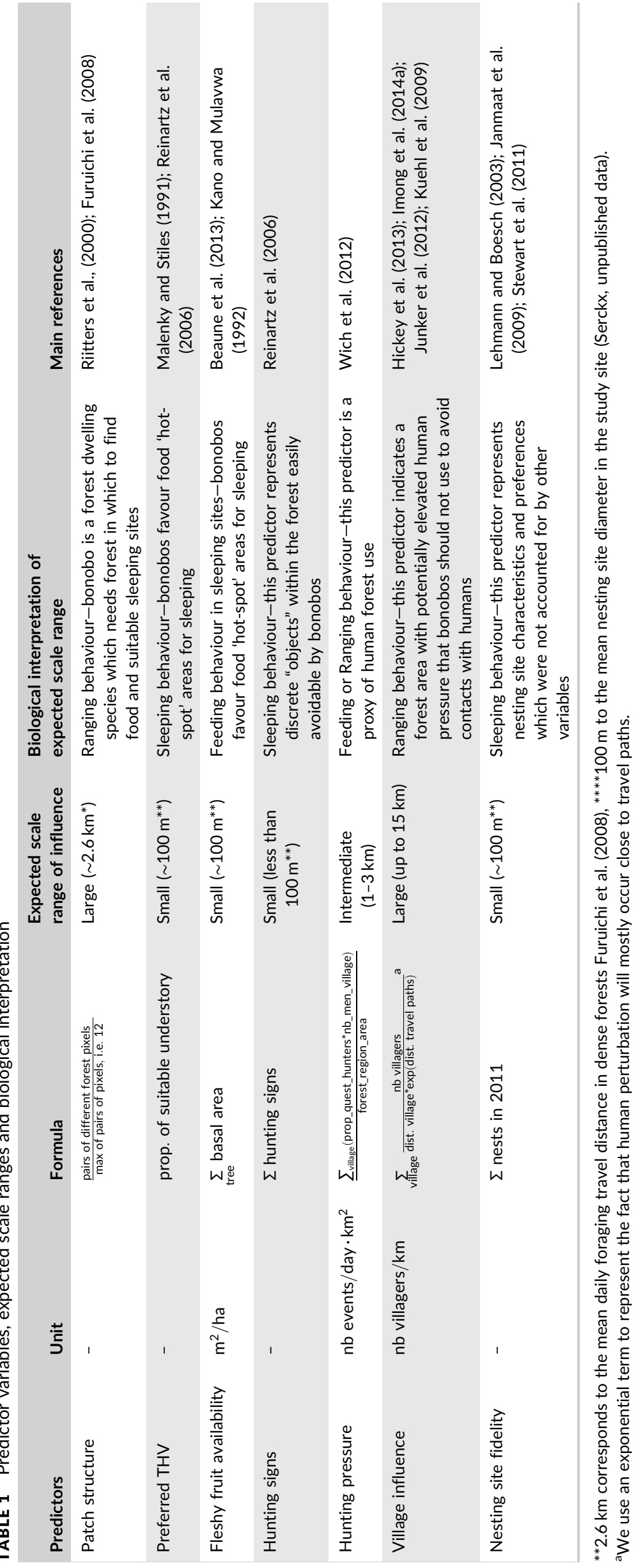


overall value for this predictor was estimated using the mean value of different forest regions covering areas of several square kilometres ( mean region area $=2.5 \mathrm{~km}^{2}$; range $=0.1-10 \mathrm{~km}^{2}$ ) and represented the use of forests by humans during the day. We assumed that this predictor would indicate human avoidance of certain forest regions at intermediate spatial scales (1-3 km) (Wich et al., 2012). Third, we used the 'village influence' predictor, a composite measure consisting of the influence of the population size of each village and the closest forest path or road, weighted by the distance to the transect segment (Appendix 4). As village size is known to influence ape density even at a large distance (Murai et al., 2013; Imong et al., 2014a,b), we used all of the villages of the study site (up to $15 \mathrm{~km}$ distant) to estimate the value for each segment.

\subsection{4 | Model building}

In order to build an appropriate model of bonobo distribution, we needed to consider several issues. First, in order to account for the skewed distribution of the number of bonobo nests on the transect segments, we used Generalized Linear Models (GLMs) with a negative binomial error function (Mc Cullagh \& Nelder, 1989). Second, we wanted to convert our response, 'nest counts', into actual density of bonobos. We therefore included an offset term into our model. This term transforms nest counts into nest density by accounting for the variable length of the transect segments and for the effective strip width, which was estimated to be $19 \mathrm{~m}$ for this survey (see Buckland et al., 2001; Hedley \& Buckland, 2004; Serckx et al., 2014). Then, in order to convert nest density into bonobo density, we assumed a nest construction rate of 1.37 per day (Mohneke \& Fruth, 2008), a proportion of nest-builders of 0.75 (because infants sleep in their mother's nest (Fruth, 1995), and a site specific mean nest decay time of 183 days (Serckx et al., 2014). Third, and counter-intuitively, we expected 'preferred THV' and 'fleshy fruit availability' to have a negative influence on bonobo density when these two predictors are present together in the forest. Locations with high proportions of 'preferred THV' and high values of 'fleshy fruit availability' are Marantaceae forests. This habitat type is often characterised by high food availability. It contains mainly trees with DBHs above $50 \mathrm{~cm}$ but also has a low density of suitable nesting trees, because bonobos prefer trees with relatively small DBHs (Fruth, 1995) (for our study site, the mean $\mathrm{DBH}$ in this forest type was $22 \mathrm{~cm}$ (Serckx, unpublished data). Mature or secondary forests, on the other hand, are characterised as being composed of trees with variable $\mathrm{DBH}$ s and of some regions with a high density of 'preferred THV'. These regions have lower 'fleshy fruit availability' but are expected to have a high density of suitable nesting trees. Thus, we added an interaction between the two predictors. Last, we needed to account for spatial autocorrelation. We used the average of the residuals of all other transect segments derived from the full model, weighted by distance as an additional predictor. The weight function had the shape of a Gaussian distribution with a mean of zero (maximal weight at distance zero) and a standard deviation was chosen such that the likelihood of the full model with the derived variable ('autocorrelation term') included was maximized (Fürtbauer, Mundry, Heistermann, Schülke, \& Ostner, 2011). The general model formulation was

$$
E\left(n_{i}\right)=\exp \left[\ln (\text { offset })+\beta_{0}+\sum_{k} \beta_{k} Z_{i k}+\beta_{a c} \text { ac } i\right.
$$

where $E\left(n_{i}\right)$ is the expected number of nests on segment $i ; \beta_{0}, \beta_{k}, \beta_{a c}$ are the parameters to be estimated for the intercept, for each predictor variable and for the autocorrelation term, respectively; $Z_{i k}$ are the vectors of values for the $k$ predictors on segment $i, a c_{i}$ is the autocorrelation term for segment $i$, and err.term is the negative binomial error function. In this study, the linear predictor became

hunting signs + hunting pressure + village influence + patch structure

+ nesting site fidelity + preferred THV + fleshy fruit availability

+ interaction(preferred THV $\times$ fleshy fruit availability)

\subsection{5 | Predictor scales and final set of models}

We evaluated the variation in importance of differing spatial scales for the three environmental predictors: 'patch structure', 'fleshy fruit availability' and 'preferred THV'. All other predictors (i.e. hunting signs, hunting pressure, village influence, nesting site fidelity) were extracted only for a single scale. For each of the three predictors, we defined a set of spatial scales to be included, with an emphasis on a large spatial scale for 'patch structure' (buffer radiuses around transect segments of 60 , 210, 600, 750, 900, 1200, 1050, 1500, 1800, 2100, 1950, 2400 and $2700 \mathrm{~m}$ ) and on a small spatial scale for 'preferred THV' (30, 60, 120, $210,300,360,600,1500$ and $2400 \mathrm{~m}$ ) and 'fleshy fruit availability' (30, $60,120,210,300,360,450,600,1500$ and $2400 \mathrm{~m}$ ). The thresholds of 60 and $2700 \mathrm{~m}$ were based on the minimum resolution of data $(50 \mathrm{~m})$ and bonobo home range size, respectively. We extracted predictor values for each buffer using (i) the arithmetic mean of values in the extracted buffer and using (ii) the weighted mean based on a Gaussian distance weighting function of all values in the buffer. As Aue et al. (2012) demonstrated, a Gaussian weighting function is the most realistic function to represent the decreasing influence of environmental context with increasing distance from observation points. Instead of testing multiple Gaussian weighting functions by varying the standard deviation as in Aue et al. (2012), we fixed the standard deviation to a third of the buffer radius for reason of computational efficiency. In this case, $99.73 \%$ of the predictor values within the buffer are considered (Sokal \& Rohlf, 1996). In Aue et al. (2012), only one buffer covering the entire habitat was used and the standard deviation of the Gaussian weighting function was modified. In contrast, we have chosen to use multiple buffers but to fix the standard deviation. However, in principle, both approaches should give very similar results. In essence, this technique facilitates comparisons with the models where extraction is realised with the arithmetic mean of values. Second it is computationally efficient. 
In summary, we fitted $x$ models (the sum of all possible combinations of all buffer radii defined for THV, fleshy fruit availability and forest structure). Each model with a respective set of buffer radii contained the full set of predictors given above (line 306-308). We fitted each of the $x$ models using the glm function in R (Venables \& Ripley, 2002) and then extracted results, including parameter estimates, likelihood, AIC for subsequent assessment and model comparison.

Prior to the analysis, we checked distributions of all predictors and transformed them when necessary to achieve more symmetrical distributions; 'preferred THV' and 'fleshy fruit availability' were square-root transformed, 'hunting signs', 'hunting pressure', 'village influence' and 'nesting site fidelity' were log-transformed and 'patch structure' was square-root transformed. We z-transformed all predictors to a mean of zero and a standard deviation of one to get comparable estimates and a more easily interpretable model (Schielzeth, 2010). In order to check model assumption, we first fitted a single-scale model with environmental predictors extracted over neighbourhoods around transect based on expert opinion (see Table 1, buffer radiuses of $100 \mathrm{~m}$ for 'fleshy fruit availability' and 'preferred THV', and of $2600 \mathrm{~m}$ for 'patch structure'). We visually examined correlations between predictors and calculated Spearman correlations for the set of predictors extracted over neighbourhoods around transect based on expert opinion. These were never higher than 0.52 (Appendix 5). To avoid problems due to collinearity or influential cases, we checked Variance Inflation Factors, dfbetas and leverage (Field, 2005; Quinn \& Keough, 2002), which did not reveal any problems (Appendix 5). We presumed that the model assumptions were still fulfilled as the environmental predictor values extracted at all discrete scales were highly correlated with those of the single-scale model (Appendix 5).

\subsection{6 | Model inference}

We drew inferences from the entire set of models comprising the three environmental predictors. For this, we calculated the weighted mean of each parameter estimate by weighting the parameter estimate of each model with the respective Akaike weight of the model. We further calculated the weighted standard error for each parameter estimate in the same way. We visually investigated change in predictor significance across the set of models.

All analyses were conducted using R (R Core Team, 2013); we used the 'glm.nb' function from the package MASS (Venables \& Ripley, 2002) to fit the models, the package 'gtools' (Warnes, Bolker, \& Lumley, 2013) to derive the autocorrelation term, and the package 'car' (Fox \& Weisberg, 2011) for model diagnostics.

\section{$2.4 \mid$ Research ethics}

This non-invasive research was part of a $\mathrm{PhD}$ project which was conducted using only indirect signs of bonobo presence (nests) under the WWF-DRC research permit (RM441976, granted by the Minister of Foreign Affairs and International Cooperation of Democratic Republic of Congo). Research complies with the Animal Care and Ethic Committee of the Biology Department of the Unikin (University of Kinshasa), American Society of Primatologists Principles for Ethical
Treatment of Nonhuman Primates and RDC Wildlife Authority regulations.

\section{3 | RESULTS}

'Patch structure' clearly influenced bonobo nest density when containing a neighbourhood of at least $750 \mathrm{~m}$ and up to $2700 \mathrm{~m}$ (hereby referred as its 'suitable scale range'). It became especially important between 1200 and $2700 \mathrm{~m}$ (upper plateau in the predictor-response curve, Figure 3). In contrast, both predictors of food availability, 'preferred THV' and 'fleshy fruit availability' had a larger influence on bonobo nest density at smaller spatial scales. Their influence decreased when larger neighbourhoods were included and they were particularly relevant when considering distances up to 300 and $600 \mathrm{~m}$, respectively (Figure 3). The general pattern for the three predictors remained largely the same when using the arithmetic or distance weighted mean of predictors (Table 2, Figure 3). The largest difference occurred for the predictor 'forest structure'. Models containing the distance weighted mean of this predictor showed a smoother trend in the model likelihoods with increasing size of predictor extraction neighbourhoods compared to the set of models containing sets of predictors based on arithmetic means. The models also revealed that bonobos preferred to nest on previously used nesting locations, indicated by the importance of the variable 'nesting site fidelity' across all models. All three human impact predictors showed no influence and remained non-significant (Table 2 ).

The parameter estimates derived for models based on the arithmetic mean of predictors did not differ much from the estimated parameters for model based on the distance weighted mean of predictors (Table 2). Predictor significance remained stable with the exception of a few models (Appendix 6), in which $p$-values of 'patch structure' and 'fleshy fruit availability' were between 0.05 and 0.11 .

\section{4 | DISCUSSION}

Our study revealed the spatially dependent relationships between bonobo nesting site preference and different environmental context. Bonobos prefer nesting sites which are surrounded by at least $750 \mathrm{~m}$ of forest, however, larger forested neighbourhoods are even better. Within this habitat bonobo nest are found in patches of high fruit availability and preferred THV, which decrease in importance beyond 600 and $300 \mathrm{~m}$ respectively. The identified spatial scale ranges correspond well to observed scales of bonobo ranging, feeding and nesting behaviour. Previously identified environmental predictors of bonobo nest distribution were fruit availability (Mulavwa et al., 2010) and THV (Reinartz et al., 2006). However, relevant scale ranges of those predictors were not identified. This is where our study can make a contribution. While environmental predictors are already known to be important for explaining nest distribution of bonobos (Mulavwa 
Patch structure
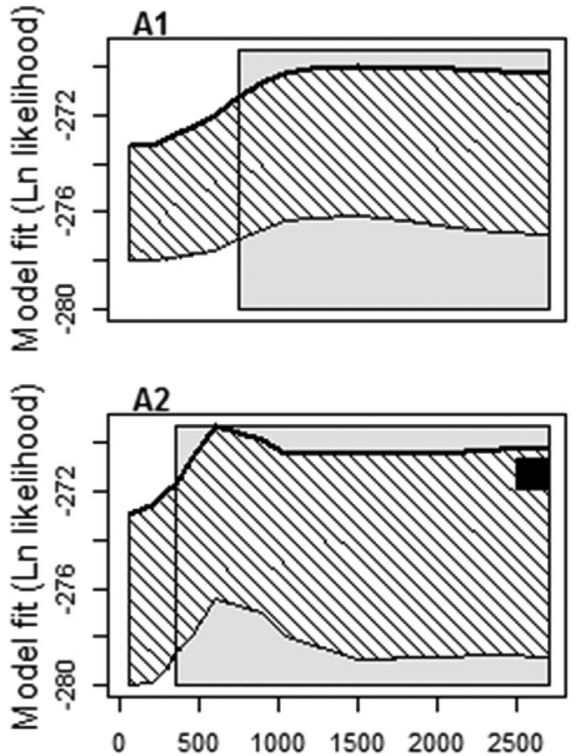

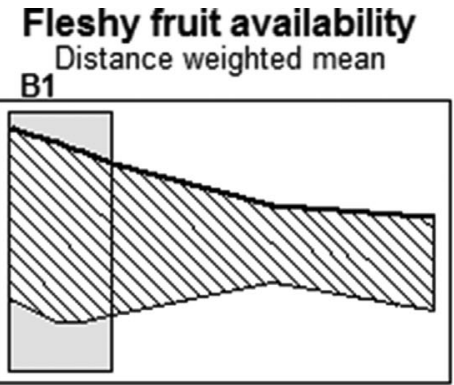

Arithmetic mean

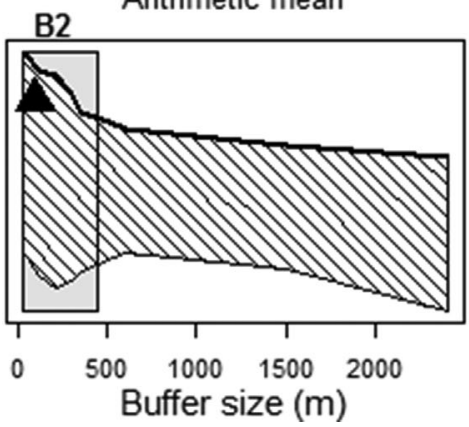

Preferred THV

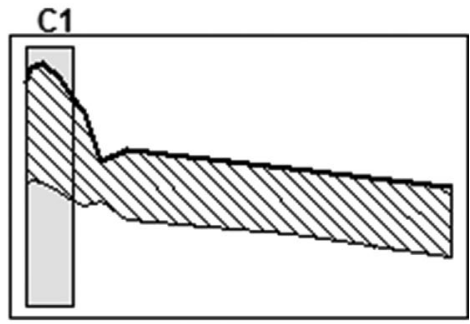

C2

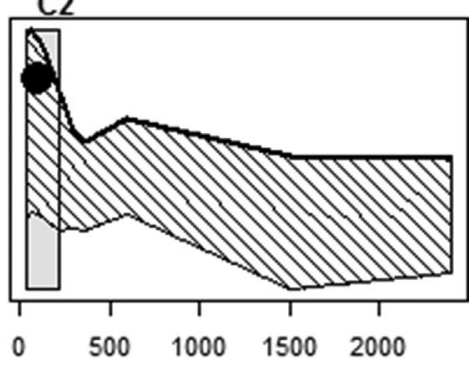

FIGURE 3 Spatial scale patterns for environmental predictors. The maximized model likelihood for spatial scale ranges of the three predictors is represented by the bold solid curve (the upper curve of the dashed polygon) for (1) distance-weighted mean predictors and (2) the arithmetic mean of predictors. The dashed polygons shows the model likelihoods of all the models evaluated. The large variation in model fit is due to the inclusion of less suitable spatial scales. The light grey boxes represent the suitable spatial scale ranges of each predictor. The three points (circle, square, triangle) indicate the model likelihoods of the single-scale model at the scale we predefined for each predictor based on expert opinion

et al., 2010; Reinartz et al., 2006) or other great apes (Furuichi \& Hashimoto, 2004; Imong et al., 2014b; Sawyer \& Brashares, 2013; Torres et al., 2010), identifying their scale ranges may help to manage forest for conservation purposes. Understanding forest minimal requirements for nesting is especially important in forest-savannah mosaics and in the context of forest degradation by humans. Scale information is also very valuable in the context of forest management in logging concessions: minimum and maximum scale ranges of

TABLE 2 Results of scale range spatial models

\begin{tabular}{|c|c|c|c|}
\hline & & $\begin{array}{l}\text { Models with distance weighting } \\
\text { function of predictors }\end{array}$ & $\begin{array}{l}\text { Models with arithmetic } \\
\text { mean of predictors }\end{array}$ \\
\hline & Variables & Estimates & Estimates \\
\hline \multirow[t]{6}{*}{ Test predictors } & Patch structure & $0.97 \pm 0.005^{* *}$ & $0.95 \pm 0.008^{* *}$ \\
\hline & Influential Scale range & $750-2700 m$ & $360-2700 m$ \\
\hline & Influential Scale range & $30-600 m$ & $30-450 m$ \\
\hline & Preferred THV & $0.87 \pm 0.003^{* *}$ & $0.89 \pm 0.004^{* *}$ \\
\hline & Influential Scale range & $30-300 \mathrm{~m}$ & $30-210 m$ \\
\hline & Interaction Fruit and THV & $-0.88 \pm 0.003^{* *}$ & $-0.89 \pm 0.005^{* *}$ \\
\hline \multirow[t]{4}{*}{ Control predictors } & Hunting signs & $-0.01 \pm 0.002$ & $-0.01 \pm 0.003$ \\
\hline & Autocorrelation term & $0.50 \pm 0.002^{*}$ & $0.48 \pm 0.008^{*}$ \\
\hline & $\mathrm{Nb}$ of parameters ${ }^{\mathrm{a}}$ & 14 & 11 \\
\hline & AIC & $566-575.1$ & $558.5-571.7$ \\
\hline
\end{tabular}

'The number of parameters accounts for the intercept, the seven predictors, the interaction between 'fleshy fruit availability' and 'preferred THV', the autocorrelation term, the theta parameter of the negative binomial error function, and, when applied, the distance weighted function for predictor extraction. Parameter estimates for scale range models are Akaike weighted estimates of all single models in the $95 \%$ confidence set; ${ }^{*}$ indicate if the predictor was significant through all scale range models $\left({ }^{* *}\right.$ highlights predictors which were only significant within their influential spatial scale ranges). 


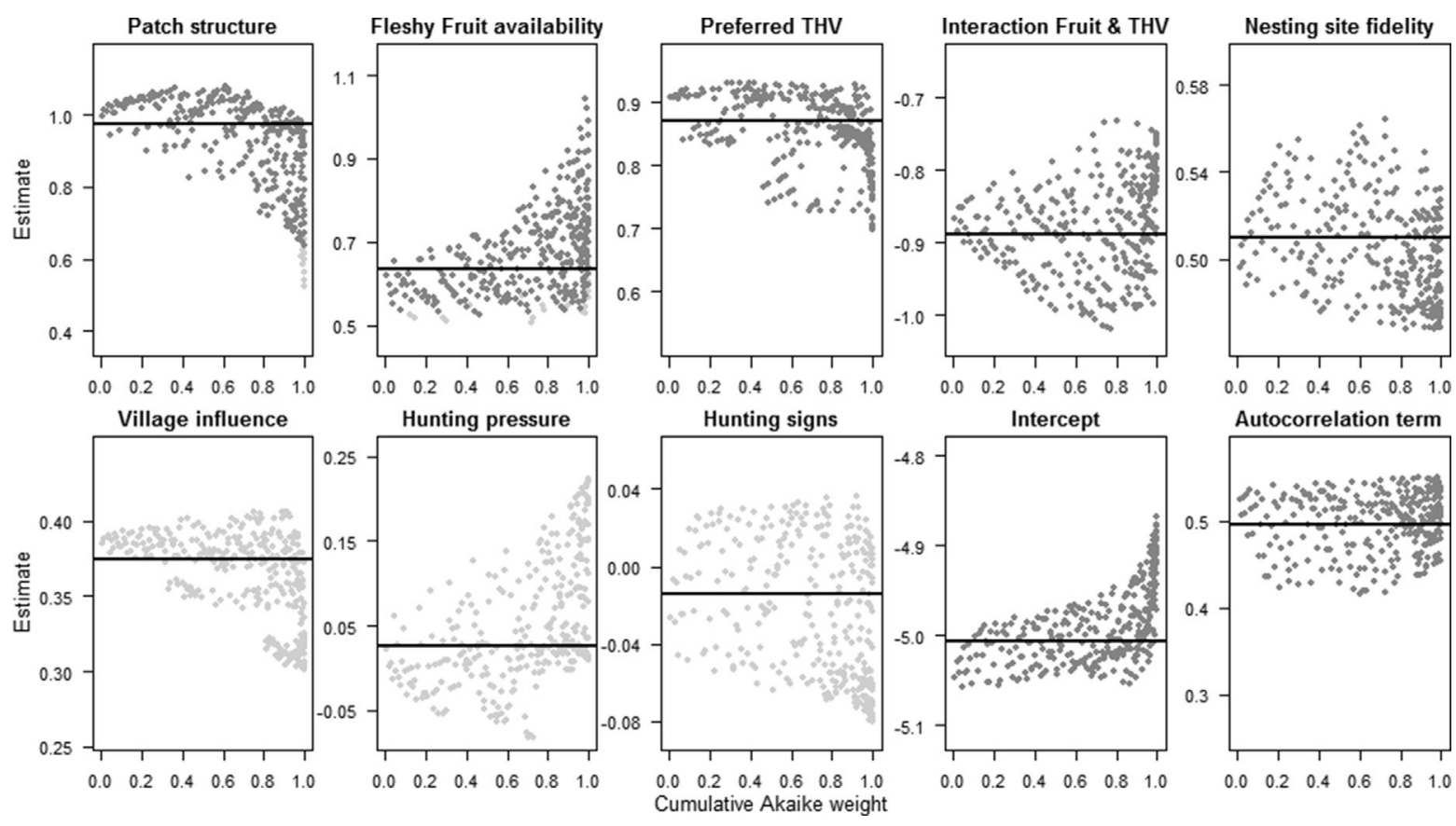

FIGURE 4 Variation in parameter influence. Parameter estimates are presented according to the cumulative Akaike weight of the models ( $X$-axis) within the suitable spatial scale ranges of the three environmental predictors. Dark grey points represent significant parameters with $p$-values $<0.05$. Light grey points represent non-significant ones. The horizontal lines indicate the global mean weighted estimates of the parameters. Predictor significance remained stable across the entire range of spatial scales with the exception of a few models where 'patch structure' and 'fleshy fruit availability' showed $p$-values between 0.05 and 0.11

preferred nesting site attributes will help to reduce the impact of logging on great apes.

\subsection{Interpreting spatial scale information}

When interpreting results on spatial scales in species-distribution models, it is commonly not realistic to select a single model representing a particular scale. Due to spatial autocorrelation of environmental context a large number of models representing the asymptotic part of sigmoid predictor scale-response relationships can fit the data similarly well. This is because there are minimum or maximum requirements for specific ecological or environmental conditions, such as area size of suitable habitat, size of feeding and roosting spots and quantity of food resources. For example, bonobos as a mainly forest dwelling species require a minimum area of forest to serve as their home range. Within this habitat matrix the spatial (and temporal) variation in food resource availability is driving bonobo ranging and nesting.

As a consequence, the commonly practised selection of a "best model' for interpreting relationships between response and predictor variables is not sufficient when evaluating a set of models based on different predictor scales. Rather such modelling approach requires an extended interpretation of model results. In particular, it needs a careful evaluation of the gradient of predictor influence with increasing or decreasing distance away from points of observation. To our knowledge there are currently no standard quantitative approaches available and a more qualitative assessment may be applied.
We dealt with this issue by drawing inferences from the full set of models and not just from a selected single-scale model alone. Such a set of models has proven to be quite useful in analysing consistency in model results (Burnham \& Anderson, 2002). In our study, models including the suitable spatial scale ranges of the three environmental predictors showed very little variation in predictor influence (Figure 4). In contrast, models outside of those suitable ranges, presented much larger variation in predictor estimates (Appendix 7). In the case of 'patch structure' and 'preferred THV', the predictors were no longer significant. In contrast, the influence of 'fleshy fruit availability' remained significant independent of spatial scale. This suggests the possibility that the predictor 'fleshy fruit availability', as we have built it, may represent differential impacts of alternative ecological conditions, i.e. fruit availability on the small scale and forest characteristics such as forest structure on the larger scale.

\section{2 | Conclusion and application}

The suggested approach holds much promise for fitting even very complex ecological models, with a wide range of potential applications, such as in basic ecological and behavioural research, or in applied disciplines like conservation or landscape management.

The search for suitable scale ranges of predictor influence is an essential tool with the potential for application in a number of fields. It promises to be useful in fields such as global landscape modification, in the context of better understanding the impact of habitat fragmentation on animal survival (Santos-Filho, Peres a., Silva, \& Sanaiotti, 2012) and 
distribution (Imong et al., 2014a; Torres et al., 2010), habitat quality within patches (Thornton, Branch, \& Sunquist, 2010) and between patches (Gray et al., 2010; Watling, Nowakowski, Donnelly, \& Orrock, 2011) and the effect of patch sizes and isolation (Anzures-Dadda \& Manson, 2007; Prugh, Hodges, Sinclair, \& Brashares, 2008). For example, the spatial pattern of patch structure in our study revealed that bonobos living in forest-savannah mosaics tend to avoid forest patches smaller than $4.5 \mathrm{~km}^{2}$ (a circular area of about $1.2 \mathrm{~km}$ ). This finding could be investigated further by accounting separately for forest patch shape and size as well as possible negative edge effects (ArroyoRodríguez \& Dias, 2010, Hickey et al., 2013; Nams, 2012). Information of this kind should be particularly useful in conservation-related landscape management (Nams et al., 2006), and to assess the impact of logging on faunal biodiversity (e.g. the effects of the opening of logging roads) (Clark, Poulsen, Malonga, \& Elkan, 2009; Laurance et al., 2008; Laurance, Goosem, \& Laurance, 2009; Nasi, Billand, \& van Vliet, 2012).

The proposed approach is not limited to the spatial scale, but can also be applied in the temporal domain. The use of weighting functions is particularly useful for studying animal relationships over extensive periods, e.g. to better understand behaviours favouring dyadic affiliations such as grooming reciprocity in primates

\section{ACKNOWLEDGEMENTS}

This project was funded by the National Fund for Scientific Research (FNRS, Belgium), the Fonds Leopold III from the Royal Belgian Institute of Natural Sciences (Belgium) and the Ecole Régionale PostUniversitaire d'Aménagement et de Gestion Intégrés des Forêts et Territoires Tropicaux (ERAIFT, Democratic Republic of Congo). We would like to thank WWF-DRC, and especially Petra Lahann, for their support in the field, as well as the Minister of Foreign Affairs and International Cooperation of The Democratic Republic of The Congo who permitted us to conduct our research. We are also grateful to Fiona Maisels and Celine Devos for their invaluable assistance with the design of our study. This research would not have been possible without the help of our local field guides. Ciceron Mbuoli Mbenkira deserves a special thank you for his incredible work during the entire research period. We also thank the Robert Bosch Foundation, the Max Planck Society, Barbara Fruth and Gottfried Hohmann from the Lui Kotal Project for their contribution of data, Roger Mundry for his statistical advice and Cleve Hicks for his feedback and suggestions. Finally, we thank our anonymous reviewers for their helpful comments.

\section{REFERENCES}

Anderson, P., Turner, M. G., Forester, J. D., Zhu, J., Boyce, M. S., Beyer, H., \& Sotwell, L. (2005). Scale-dependent summer resource selection by reintroduced elk in Wisconsin, USA. The Journal of Wildlife Management, 69, 298-310.

Anzures-Dadda, A., \& Manson, R. H. (2007). Patch- and landscape-scale effects on howler monkey distribution and abundance in rainforest fragments. Animal Conservation, 10, 69-76.

Araújo, M. B., \& Guisan, A. (2006). Five (or so) challenges for species distribution modelling. Journal of Biogeography, 33, 1677-1688.

Arroyo-Rodríguez, V., \& Dias, P. A. D. (2010). Effects of habitat fragmentation and disturbance on howler monkeys: a review. American Journal of Primatology, 72, 1-16.
Aue, B., Ekschmitt, K., Hotes, S., \& Wolters, V. (2012). Distance weighting avoids erroneous scale effects in species-habitat models. Methods in Ecology and Evolution, 3, 102-111.

Basabose, A. K. (2002). Diet composition of Chimpanzees inhabiting the montane forest of Kahuzi, Democratic Republic of Congo. American Journal of Primatology, 58, 1-21.

Beaune, D., Bretagnolle, F., Bollache, L., Bourson, C., Hohmann, G., \& Fruth, B. (2013). Ecological services performed by the bonobo (Pan paniscus): seed dispersal effectiveness in tropical forest. Journal of Tropical Ecology, 29, 367-380.

Bourland, N., Koudia Yao, L., Lejeune, P., Sonké, B., Philippart, J., Daïnou, K., ... Doucet, J.-L. (2012). Ecology of Pericopsis elata (Fabaceae), an endangered timber species in southeastern Cameroon. Biotropica, 44, 840-847.

Bowyer, R. T., \& Kie, J. G. (2006). Effects of scale on interpreting life-history characteristics of ungulates and carnivores. Diversity and Distributions, 12, 244-257.

Boyce, M. S. (2006). Scale for resource selection functions. Diversity and Distributions, 12, 269-276.

Boyer, D., Ramos-Fernández, G., Miramontes, O., Mateos, J. L., Cocho, G., Larralde, H., ... Rojas, F. (2006). Scale-free foraging by primates emerges from their interaction with a complex environment. Proceedings of the Royal Society of Biological Sciences, 273, 1743-1750.

Buckland, S. T., Anderson, D. R., Burnham, K. P., Laake, J. L., Borchers, D. L., \& Thomas, L. (2001). Introduction to distance sampling: estimating abundance of biological populations. Oxford: Oxford University Press.

Burnham, K. P., \& Anderson, D. R. (2002). Model selection and multimodel inference a practical information-theoretic approach (2nd ed.). New York: Springer.

Clark, C. J., Poulsen, J. R., Malonga, R., \& Elkan, P. W. (2009). Logging concessions can extend the conservation estate for Central African tropical forests. Conservation Biology: The Journal of the Society for Conservation Biology, 23, 1281-1293.

Djoufack, S. D., Nkongmeneck, B. A., Dupain, J., Bekah, S., Bombome, K. K., Epanda, M. A., \& Van Elsacker, L., Editors. (2007). Manuel d'identification des fruits consommés par les gorilles et les chimpanzés des basses terres de l'Ouest; Espèces de l'écosystème du Dja (Cameroun).

Doucet, J.-L. (2003). PhD Thesis. L'alliance délicate de la gestion forestière et de la biodiversité dans les forêts du centre du Gabon. 390.

Field A. (2005). Discovering statistics using SPSS. London: Sage Publications.

Fischer, J., \& Lindenmayer, D. B. (2006). Beyond fragmentation: the continuum model for fauna research and conservation in humanmodified landscapes. Oikos, 2, 473-480.

Forester, J. D., Kyung Im, H., \& Rathouz, P. J. (2009). Accounting for animal movement in estimation of resource selection functions: sampling and data analysis. Ecology, 90, 3554-3565.

Forstmeier, W, \& Schielzeth, H. (2011). Cryptic multiple hypotheses testing in linear models: overestimated effect sizes and the winner's curse. Behavioral Ecology and Sociobiology, 65, 47-55.

Fortin, D., Beyer, H., Boyce, M., \& Smith, D. (2005). Wolves influence elk movements: behavior shapes a trophic cascade in Yellowstone National Park. Ecology, 86, 1320-1330.

Fox, J, \& Weisberg, S. (2011). An $R$ companion to applied regression. Thousand Oaks, CA: Sage.

Fruth B. (1995). PhD Thesis. Nests and nest groups in wild bonobos: ecological and behavioural correlates. p. 187.

Fürtbauer, I., Mundry, R., Heistermann, M., Schülke, O., \& Ostner, J. (2011). You mate, I mate: macaque females synchronize sex not cycles. PloS ONE, 6, e26144.

Furuichi, T., \& Hashimoto, C. (2004). Botanical and topographical factors influencing nesting-wste selection by Chimpanzees in 
Kalinzu Forest, Uganda. International Journal of Primatology, 25, 755765.

Furuichi, T., Mulavwa, M., Yangozene, K., Motema-salo, B., Idani, G., \& Ihobe, H. (2008). Relationships among fruit abundance, ranging rate, and party size and composition of bonobos at Wamba. In T. Furuichi, \& J. Thompson (Eds.), The bonobos: behavior, ecology, and conservation (pp. 135-149). New York: Springer.

Gray, T. N. E., Phan, C., \& Long, B. (2010). Modelling species distribution at multiple spatial scales: gibbon habitat preferences in a fragmented landscape. Animal Conservation, 13, 324-332.

Guisan, A., \& Edwards, T. C. (2002). Generalized linear and generalized additive models in studies of species distributions: setting the scene. Ecological Modelling, 157, 89-100.

Guisan, A., \& Zimmermann, N. E. (2000). Predictive habitat distribution models in ecology. Ecological Modelling, 135, 147-186.

Hedley, S. L., \& Buckland, S. T. (2004). Spatial models for line transect sampling. Journal of Agricultural, Biological, and Environmental Statistics, 9, 181-199.

Henry, M., Fröchen, M., Maillet-Mezeray, J., Breyne, E., Allier, F., \& Odoux, J.-F. (2012). Spatial autocorrelation in honeybee foraging activity reveals optimal focus scale for predicting agro-environmental scheme efficiency. Ecological Modelling, 225, 103-114.

Hickey, J. R., Nackoney, J., Nibbelink, N. P., Blake, S., Bonyenge, A., Coxe, S., ... Kühl, H. S. (2013). Human proximity and habitat fragmentation are key drivers of the rangewide bonobo distribution. Biodiversity and Conservation, 22, 3085-3104.

Imong, I., Robbins, M. M., Mundry, R., Bergl, R., \& Kühl, H. S. (2014a). Distinguishing ecological constraints from human activity in species range fragmentation: the case of Cross River gorillas. Animal Conservation, 17, 323-331.

Imong, I., Robbins, M. M., Mundry, R., Bergl, R., \& Kühl, H. S. (2014b). Informing conservation management about structural vs. functional connectivity: a case study of Cross River gorillas. American Journal of Primatology, 76, 978-988.

Inogwabini B., Bewa M., Longwango M., Abokome M., \& Vuvu M., (2008). The Bonobos of the Lake Tumba-Lake Maindombe Hinterland: threats and opportunities for population conservation. In T. Furuichi, \& J. Thompson (Eds.), The bonobos: behavior, ecology, and conservation (pp. 273-290). New York: Springer.

Janmaat, K. R. L., Olupot, W., Chancellor, R. L., Arlet, M. E., \& Waser, P. M. (2009). Long-term site fidelity and individual home range shifts in Lophocebus albigena. International Journal of Primatology, 30, 443-466.

Johnson, C., Boyce, M., Mulders, R., \& Gunn, A. (2004a). Quantifying patch distribution at multiple spatial scales: applications to wildlife-habitat models. Landscape Ecology, 29, 869-882.

Johnson, C. J., Parker, K. L., Heard, D. C., \& Gillingham, M. P. (2004b). A multiscale behavioral approach to understanding the movements of woodland Caribou. Ecological Applications, 12, 1840-1860.

Johnson, C. J., Seip, D. R., \& Boyce, M. S. (2004c). A quantitative approach to conservation planning: using resource selection functions to map the distribution of mountain caribou at multiple spatial scales. Journal of Applied Ecology, 41, 238-251.

Junker, J., Blake, S., Boesch, C., Campbell, G., Du Toit, L., Duvall, C., ... Kuehl, H. S. (2012). Recent decline in suitable environmental conditions for African great apes. Diversity and Distributions, 18, 1077-1091.

Kano, T, \& Mulavwa, M., (1992). Appendix. In T. Kano (Ed.), The last ape: pygmy chimpanzee behavior and ecology (pp. 225-232). Stanford: Stanford University Press.

Kideghesho, J. R., Røskaft, E., \& Kaltenborn, B. P. (2006). Factors influencing conservation attitudes of local people in Western Serengeti, Tanzania. Biodiversity and Conservation, 16, 2213-2230.
Kie, J. G., Bowyer, R. T., Nicholson, M. C., Boroski, B. B., \& Loft, E. R. (2002). Landscape heterogeneity at differing scales: effects on spatial distribution of Mule Deer. Ecology, 83, 530-544.

Kouakou, C. Y., Boesch, C., \& Kuehl, H. S. (2011). Identifying hotspots of chimpanzee group activity from transect surveys in Taï National Park, Côte d'Ivoire. Journal of Tropical Ecology, 27, 621-630.

Kuehl, H., Maisels, F., Ancrenaz, M., \& Williamson, E. (2008). Best practice guidelines for surveys and monitoring of great ape populations. Gland: Switzerland.

Kuehl, H. S., Nzeingui, C., Le Duc Yeno, S., Huijbregts, B., Boesch, C., \& Walsh, P. D. (2009). Discriminating between village and commercial hunting of apes. Biological Conservation, 142, 1500-1506.

Laurance, W. F., Croes, B. M., Guissouegou, N., Buij, R., Dethier, M., \& Alonso, A. (2008). Impacts of roads, hunting, and habitat alteration on nocturnal mammals in African rainforests. Conservation Biology: The Journal of the Society for Conservation Biology, 22, 721-732.

Laurance, W. F., Goosem, M., Laurance, S. G. W. (2009). Impacts of roads and linear clearings on tropical forests. Trends in Ecology \& Evolution, 24, 659-669.

Lehmann, J., \& Boesch, C. (2003). Social influences on ranging patterns among chimpanzees (Pan troglodytes verus) in the Tai National Park, Cote d'Ivoire. Behavioral Ecology, 14, 642-649.

Levin, S. A. (1992). The problem of pattern and scale in ecology: the Robert H. MacArthur award lecture. Ecology, 73, 1943-1967.

Madron De, L. D., \& Daumerie, A. (2004). Diamètre de fructification de quelques essences en forêt naturelle centrafricaine. Bois Et Forêts Des Tropiques, 281, 87-95.

Malenky, R. K., \& Stiles, E. W. (1991). Distribution of terrestrial herbaceous vegetation and its consumption by Pan paniscus in the Lomako Forest, Zaire. American Journal of Primatology, 169, 153-169.

Marceau, D. J. (1999). The scale issue in social and natural sciences. Canadian Journal of Remote Sensing, 25, 347-356.

Marceau, D. J., \& Hay, G. J. (1999). Scaling and modelling in forestry: applications in remote sensing and GIS. Canadian Journal of Remote Sensing, 25, 342-346.

Mayor, A. S. J., Schaefer, J. A., Schneider, D. C., Mahoney, S. P., \& Mayor, S. J. (2007). Spectrum of selection: new approaches to detecting the scale-dependent response to habitat. Ecology, 88, 1634-1640.

Mayor, S. J., Schneider, D. C., Schaefer, J. A., \& Mahoney, S. P. (2009). Habitat selection at multiple scales. Ecoscience, 16, 238-247.

Mc Cullagh P., \& Nelder J. A. (1989). Generalized linear models. Monographs. London: Chapman and Hall/CRC.

Menga, P., Bayol, N., Nasi, R., \& Fayolle, A. (2012). Phenology and fructification diameter in wenge, Millettia laurentii de wild: management implications. Bois Et Forêts Des Tropiques, 66, 31-42.

Meyer, C. B., \& Thuiller, W. (2006). Accuracy of resource selection functions across spatial scales. Diversity and Distributions Distributions, 12, 288-297.

Mohneke, M, \& Fruth, B., (2008). Bonobo (Pan paniscus) density estimation in the SW-Salonga National Park, Democratic Republic of Congo: common methodology revisited. In T. Furuichi, \& J. Thompson (Eds.), The bonobos: behavior, ecology, and conservation (pp. 151-166). New York: Springer.

Mulavwa, M., Yangozene, K., Yamba-Yamba, M., Motema-Salo, B., Mwanza, N., \& Furuichi, T. (2010). Nest groups of wild bonobos at Wamba: selection of vegetation and tree species and relationships between nest group size and party size. American Journal of Primatology, 71, 1-12.

Mundry, R., \& Nunn, C. L. (2009). Stepwise model fitting and statistical inference: turning noise into signal pollution. The American Naturalist, $173,119-123$. 
Murai, M., Ruffler, H., Berlemont, A., Campbell, G., Esono, F., Agbor, A., ... Kühl, H. S. (2013). Priority areas for large mammal conservation in Equatorial Guinea. PloS ONE, 8, e75024.

Murray, C. M., Gilby, I. C., Mane, S. V., \& Pusey, A. E. (2008). Adult male chimpanzees inherit maternal ranging patterns. Current Biology, $18,20-24$

Nams, V. O. (2012). Shape of patch edges affects edge permeability for meadow voles. Ecological Applications, 22, 1827-1837.

Nams, V. O., Mowat, G., \& Panian M. A. 2006. Determining the spatial scale for conservation purposes-an example with grizzly bears. Biological Conservation1, 28, 109-119.

Nasi, R., Billand, A., \& van Vliet, N. (2012). Managing for timber and biodiversity in the Congo Basin. Forest Ecology and Management, 268 , 103-111.

Nicholson, M. C., Bowyer, R. T., Kie, J. G., Journal, S., \& May, N. (1997). Habitat selection and survival of Mule Deer: tradeoffs associated with migration. Journal of Mammalogy, 78, 483-504.

Nyariki, D. M. (2009). Household data collection for socio-Economic research in agriculture: approaches and challenges in developing countries. Journal of Social Sciences, 19, 91-99.

Ordóñez-Gómez, J. D., Arroyo-Rodríguez, V., Nicasio-Arzeta, S., \& Cristóbal-Azkarate, J. (2015). Which is the appropriate scale to assess the impact of landscape spatial configuration on the diet and behavior of spider monkeys? American Journal of Primatology, 77, 56-65.

PEN Prototype Questionnaire. (2008). CIFOR:1-26. Available from: http:// www.cifor.org/fileadmin/fileupload/PEN/pubs/pdf_files/

PEN_Prototype_Questionnaire_-_version_4-4_-_September_2008.pdf

Pita, R., Mira, A., \& Beja, P. (2011). Assessing habitat differentiation between coexisting species: the role of spatial scale. Acta Oecologica, 37, 124-132.

Plumptre, A. J. (2000). Monitoring mammal populations with line transect techniques in African forests. Journal of Applied Ecology, 37, 356-368.

Prugh, L. R., Hodges, K. E., Sinclair, A. R. E., \& Brashares, J. S. (2008). Effect of habitat area and isolation on fragmented animal populations. Proceedings of the National Academy of Sciences of the United States of America, 105, 20770-20775.

Quinn, G. P., \& Keough, M. J. (2002). Experimental designs and data analysis for biologists. Cambrigde: Cambrige University Press.

R Core Team. (2013). R: a language and environment for statistical computing.

Reinartz, G. E., Inogwabini, B. I., Ngamankosi, M., \& Wema, L. W. (2006). Effects of forest type and human presence on bonobo (Pan paniscus) density in the Salonga National Park. International Journal of Primatology, 27, 1229-1231.

Rhodes, J., McAlpine, C., Lunney, D., \& Possingham, H. (2005). A spatially explicit habitat selection model incorporating home range behavior. Ecology, 86, 1199-1205.

Rhodes, J. R., Mcalpine, C. A., Zuur, A. F., Smith, G. M., \& leno E. N., (2009). GLMM applied on the spatial distribution of Koalas in a fragmented landscape. In A. F. Zuur, E. N. leno, N. J. Walker, A. A. Saveliev, \& G. M. Smith (Eds.), Mixed effects models and extensions in ecology with $R$ (pp. 469-492).New York: Springer.

Riitters, K., Wickham, J., Neill, R. O., Jones, B., \& Smith, E. (2000). Global-scale patterns of forest fragmentation. Conservation Ecology, 4, 1-18.

Santos-Filho, M., Peres, C. A., Silva, D. J., \& Sanaiotti, T. M. (2012). Habitat patch and matrix effects on small-mammal persistence in Amazonian forest fragments. Biodiversity and Conservation, 21, 1127-1147.

Sawyer, S. C., \& Brashares, J. S. (2013). Applying resource selection functions at multiple scales to prioritize habitat use by the endangered Cross River gorilla. Diversity and Distributions, 19, 943-954.
Schielzeth, H. (2010). Simple means to improve the interpretability of regression coefficients. Methods in Ecology and Evolution, 1, 103-113.

Seo, C., Thorne, J. H., Hannah, L., \& Thuiller, W. (2009). Scale effects in species distribution models: implications for conservation planning under climate change. Biology Letters, 5, 39-43.

Serckx, A. (2014). Eco-ethology of a population of bonobos (Pan paniscus) living in the western forest-savannah mosaics of the Democratic Republic of Congo. 277.

Serckx, A., Huynen, M.-C., Bastin, J.-F., Beudels-Jamar, R. C., Hambuckers, A., Vimond, M., ... Kühl, H. S. (2014). Nesting patterns of bonobos (Pan paniscus) in relation to fruit availability in a forest-savannah mosaic. PloS ONE, 9, e93742.

Serckx, A., Kühl, H. S., Beudels-Jamar, R. C., Poncin, P., Bastin, J. F., \& Huynen, M. C. (2015). Feeding ecology of bonobos living in forestüsavannah mosaics: diet seasonal variation and importance of fallback foods. American Journal of Primatology, 77(9), 948-962.

Shibia, M. G. (2000). Determinants of attitudes and perceptions on resource use and management of Marsabit National Reserve, Kenya. Journal of Human Ecology, 30, 55-62.

Sokal, R. S., \& Rohlf, F. J. (1996). Introduction to biostatistics. New York: W. H. Freeman and Company.

Stewart, F. A., Piel, A. K., \& McGrew, W. C. (2011). Living archaeology: artefacts of specific nest site fidelity in wild chimpanzees. Journal of Human Evolution, 61, 388-395.

Strier, K. (1989). Effets of patch size on feeding associations in muriquies (Brachyteles brachnoides). Folia Primatologica, 52, 70-77.

Tailfer, Y. (1989). La foret dense d'Afrique centrale. Identification pratique des principaux arbres, Tome 1 et 2. Wageningen, Pays-Bas: C.T.A.

Thornton, D. H., Branch, L. C., \& Sunquist, M. E. (2010). The influence of landscape, patch, and within-patch factors on species presence and abundance: a review of focal patch studies. Landscape Ecology, 26, 7-18.

Torres, J., Brito, J. C., Vasconcelos, M. J., Catarino, L., Gonçalves, J., \& Honrado, J. (2010). Ensemble models of habitat suitability relate chimpanzee (Pan troglodytes) conservation to forest and landscape dynamics in Western Africa. Biological Conservation, 143, 416-425.

Urban, D. L. (2004). Modeling ecological processes across scales. Ecology, 86, 1996-2006

van Beest, F. M., Rivrud, I. M., Loe, L. E., Milner, J. M., \& Mysterud, A. (2011). What determines variation in home range size across spatiotemporal scales in a large browsing herbivore? The Journal of Animal Ecology, 80, 771-785.

Vancutsem, C., Pekel, J., Kibamba, J.-P., Blaes, X., de Wasseige, C., \& Defourny, P. (2006). Louvain. In P. U. de (Ed.), Carte de l'occupation du sol de la République Démocratique du Congo. Bruxelles: Presses universitaires de Louvain.

Vaughan, I. P., \& Ormerod, S. J. (2003). Improving the quality of distribution models for conservation by addressing shortcomings in the field collection of training data. Conservation Biology, 17, 1601-1611.

Venables, W. N., \& Ripley, B. D. (2002). Modern applied statistics with S. New York: Springer.

Warnes, G. R., Bolker, B., \& Lumley, T. (2013). gtools: Various R programming tools.

Watling, J. I., Nowakowski, A. J., Donnelly, M. A., \& Orrock, J. L. (2011). Meta-analysis reveals the importance of matrix composition for animals in fragmented habitat. Global Ecology and Biogeography, 20, 209-217.

Wheatley, M. (2010). Domains of scale in forest-landscape metrics: implications for species-habitat modeling. Acta Oecologica, 36, 259-267.

Wheatley, M., \& Johnson, C. (2009). Factors limiting our understanding of ecological scale. Ecological Complexity, 6, 150-159. 
Whittingham, M. J., Stephens, P. A., Bradbury, R. B., \& Freckleton, R. P. (2006). Why do we still use stepwise modelling in ecology and behaviour? The Journal of Animal Ecology, 75, 1182-1189.

Wich, S. A., Fredriksson, G. M., Usher, G., Peters, H. H., Priatna, D., Basalamah, F., ... Kühl, H. (2012). Hunting of Sumatran orang-utans and its importance in determining distribution and density. Biological Conservation, 146, 163-169.

\section{APPENDICES}

Appendix 1: List of Marantaceae and THV Observed at the Study Site.

TABLE 1A List of Marantaceae and THV observed at the study site $\begin{array}{ll}\text { Scientific name } & \text { Part } \\ \text { Consumption } & \text { eaten }\end{array}$ Marantaceae

\begin{tabular}{|c|c|c|}
\hline Haumania liebrechtsiana & $\mathrm{Y}$ & $\mathrm{Fr}, \mathrm{St}, \mathrm{L}$ \\
\hline Marantochloa congensis & $\mathrm{N}$ & \\
\hline Marantochloa mannii & $\mathrm{Y}$ & St \\
\hline Marantochloa leucantha & $\mathrm{Y}$ & $\mathrm{Fr}, \mathrm{St}$ \\
\hline Marantochloa purpurea & $\mathrm{N}$ & \\
\hline Megaphrynium macrostachyum & $\mathrm{Y}$ & Fr, St \\
\hline Megaphrynium trichogynum & $\mathrm{Y}$ & St, Fr \\
\hline Hypselodelphus violacea & $\mathrm{Y}$ & $\mathrm{Fr}$ \\
\hline \multirow{2}{*}{$\begin{array}{l}\text { Sarcophrynium brachystachyum/ } \\
\text { schweinfurthianum }\end{array}$} & $\mathrm{Y}$ & $\mathrm{Fr}$ \\
\hline & $\mathrm{Y}$ & St \\
\hline Sarcophrynium prionogonium & $\mathrm{Y}$ & $\mathrm{Fr}$ \\
\hline Thaumatococcus daniellii & $\mathrm{Y}$ & Fr, St \\
\hline \multicolumn{3}{|l|}{ Zingiberaceae } \\
\hline Aframomum sp. & $\mathrm{Y}$ & Fr, St \\
\hline
\end{tabular}

'Consumption' column indicates whether the species is consumed by bonobos at the study site [Y, Yes; N, No; see Serckx et al. (2015)]. Part eaten corresponds to fruits (Fr), stems (St) or leave (L).

\section{Appendix 2: Detailed Description of Measures Taken on Tree Species During Field Data Collection}

In order to identify the dominant tree species in the canopy, we measured all trees with a DBH larger than $50 \mathrm{~cm}$ within a $10 \mathrm{~m}$ strip on both sides of the transects. We were unable to measure the $\mathrm{DBH}$ of trees covered in lianas, so we later assigned them the median DBH value found for other trees in the survey $(67 \mathrm{~cm})$. For trees with several stems at the height of DBH measurement, we summed their stem DBH measures. Finally, we decided to include in the analysis as well trees with a DBH between approximately 45 and $50 \mathrm{~cm}$. Those trees were all noted during the survey but not measured. For analysis we assigned them a DBH of $47.5 \mathrm{~cm}$, as this involved a maximum error of only $0.0002 \mathrm{~m}^{2} / \mathrm{ha}$ in the basal area calculation.

\section{Appendix 3: Overview of the Population Census and Socio-} Economic Survey in Villages Surrounding the Study Sites in 2012

We developed a questionnaire based on the "Poverty and Environment Network (PEN) Prototype Questionnaire" (PEN Prototype
Wiens, J. A. (1989). Spatial scaling in ecology. Functional Ecology, 3, 385-397.

Wilks, C. M., \& Issembe, Y. A. (2000). Les arbres de la Guinée Equatoriale: guide pratique d'identification: région continentale. Projet CUREF, Bata, Guinée Equatoriale. France: Prépresse Communications.

Woodcock, C. E., \& Strahler, A. H. (1987). The Factor of scale in remote sensing. Remote Sensing of Environment, 21, 311-332.

Questionnaire, 2008). We randomly chose a minimum of $30 \%$ of adults in all local villages and farms (Kideghesho, Røskaft, \& Kaltenborn, 2006; Nyariki, 2009; Shibia, 2000), leading to a total of 119 men and 82 women interviewed.

\section{Appendix 4: Complementary Descriptions of Our Preparation of the Predictor Variables}

\section{Forest-savannah classification map}

We realised a non-supervised classification (Red and IR) on a subset of the Landsat7 (2007) satellite imagery (Landsat ID: L71181062_06220070102; used clip: $16.38-16.62^{\circ} \mathrm{E}, 2.42-2.67^{\circ} \mathrm{S}$ ) with the software ENVI 5.0.2. We defined a pixel resolution of $50 \mathrm{~m}$ and used a k-means algorithm with 15 classes and 30 iterations. We then aggregated classes as forest versus savannah according to our knowledge from the transects. Finally, we smoothed the results using the smoothed sieve (2-8 neighbours) and clump $(3 \times 3$ pixels $)$ methods.

\section{'Human pressure' index calculation}

We derived 'human pressure' from our questionnaire data by calculating the daily number of adults who could potentially enter the region of the forest in which the $25 \mathrm{~m}$-transect segment was located. For each village, we calculated the proportion of interviewed men who said that they sometimes entered the forest region ('prop_quest_hunters' in the formula). In order to obtain this index, we first estimated the probability of a man entering a particular forest region (i.e. daily hunting frequency divided by the number of forest regions in which each person hunts) and then divided it by the number of interviewed men performing the activity. We estimated the proportion of men going to a forest region for each village and finally derived the overall index of human pressure for all villages:

Human_pressure $=\frac{\sum_{\text {village }}(\text { prop_quest_hunters*nb_men_village })}{\text { forest_region_area }}$

where nb_men_village is the number of men in a village and forest_region_area was the area of the forest region in square kilometres (used to account for differences in the sizes of the forest regions and to obtain values comparable between forest regions).

We finally calculated the mean value of the 'hunting pressure' for the transect segment.

\section{'Village influence' calculation}

In order to estimate the 'village influence', we first realised two maps in which each pixel (at $25 \mathrm{~m}$ of resolution) consisted of the Euclidean 
TABLE 3A Socio-economic data

\begin{tabular}{|c|c|c|c|c|c|c|c|c|c|c|}
\hline & & \multicolumn{5}{|c|}{ Population census } & \multicolumn{4}{|c|}{ Interviewees } \\
\hline & & $\mathrm{Nb}$ & $\mathrm{Nb}$ men & Nb women & $\mathrm{Nb}$ children & Total & Total & Men & Women & Hunters (M) \\
\hline 1 & Nkoo & 168 & 169 & 202 & 540 & 911 & 50 & 35 & 15 & 16 \\
\hline 3 & Lebomo & 37 & 37 & 34 & 141 & 212 & 26 & 14 & 12 & 7 \\
\hline 4 & Nkala & 34 & 36 & 49 & 110 & 195 & 39 & 21 & 18 & 7 \\
\hline 6 & Mavula & 10 & 10 & 12 & 25 & 47 & 6 & 3 & 3 & 3 \\
\hline 7 & Bosatore & 7 & 5 & 7 & 22 & 34 & 2 & 1 & 1 & 1 \\
\hline 8 & Mokoabuo & 6 & 5 & 8 & 17 & 30 & 4 & 2 & 2 & 1 \\
\hline 9 & Clinic of Nkoo & 4 & 4 & 4 & 19 & 27 & 2 & 1 & 1 & 0 \\
\hline 10 & Lensiana & 4 & 4 & 3 & 18 & 25 & 0 & 0 & 0 & 0 \\
\hline 13 & Motsuemontore & 2 & 2 & 4 & 9 & 15 & 2 & 1 & 1 & 1 \\
\hline 14 & Ezano & 3 & 2 & 2 & 8 & 12 & 1 & 1 & 0 & 1 \\
\hline 15 & Mayi Monene & 2 & 2 & 3 & 5 & 10 & 2 & 1 & 1 & 0 \\
\hline 16 & MMT & 4 & 4 & 4 & 2 & 10 & 2 & 1 & 1 & 0 \\
\hline 17 & Moza & 1 & 1 & 1 & 6 & 8 & 2 & 1 & 1 & 0 \\
\hline \multirow[t]{2}{*}{18} & Bosieli & 1 & 1 & 1 & 5 & 7 & 2 & 1 & 1 & 1 \\
\hline & TOTAL & 342 & 347 & 412 & 1138 & 1897 & 201 & 119 & 82 & 60 \\
\hline
\end{tabular}

Under the 'Population census' heading, we present the results of the village population census realized in 2012. Beneath the 'Interviewees' heading are indicated first the sampling effort for the collection of socio-economic data (total per village and per gender) and the number of men who answered that they regularly enter the forests for hunting. The numbers in the first column indicate the locations of villages on the map of the study site (Figure 1 in the paper).

distance either to the closest forest paths or to the closest road. We extracted for each transect segment the mean value of each parameter in a rectangle with a side of $19 \mathrm{~m}$ (corresponding to the effective strip width, Buckland et al. 2001) and used, for each transect segment, the parameter for which the value was smaller. Finally, we summed, at the middle point of each transect segment, the population size of each village divided by the distance to the village and by the exponential distance to the nearest forest path/ road. We used the exponential distance to the nearest point of forest access, as we considered that human pressure would likely be highest on the path/road but will decrease quickly as one moves away from them.

\section{Appendix 5: Examination of the Models' Assumptions}

\section{Single-scale model}

In order to check model assumption, we realised a single-scale model with environmental predictors extracted over neighbourhoods around transect based on expert opinion (see Table 1 in the paper, buffer radiuses of $100 \mathrm{~m}$ for 'fleshy fruit availability' and 'preferred THV', and of $2600 \mathrm{~m}$ for 'patch structure').

Collinearity was not an issue since Spearman correlation coefficients were never higher than 0.52 (Table 5A), and Variance Inflation Factors were below 1.58 for all variables (Table 5B; Field,

TABLE 5A Spearman correlations of the single-scale model

\begin{tabular}{|c|c|c|c|c|c|c|c|}
\hline & $\begin{array}{l}\text { Nesting site } \\
\text { fidelity }\end{array}$ & $\begin{array}{l}\text { Hunting } \\
\text { signs }\end{array}$ & $\begin{array}{l}\text { Hunting } \\
\text { pressure }\end{array}$ & $\begin{array}{l}\text { Village } \\
\text { influence }\end{array}$ & $\begin{array}{l}\text { Patch } \\
\text { structure }\end{array}$ & $\begin{array}{l}\text { Preferred } \\
\text { THV }\end{array}$ & $\begin{array}{l}\text { Fleshy fruit } \\
\text { avail. }\end{array}$ \\
\hline Nesting site fidelity & & 0.069 & 0.0082 & 0.1143 & 0.1047 & 0.3768 & 0.3414 \\
\hline Hunting signs & & & 0.045 & -0.0778 & -0.002 & 0.0962 & 0.1025 \\
\hline Hunting pressure & & & & 0.3366 & 0.3207 & 0.044 & 0.0475 \\
\hline Village influence & & & & & 0.5105 & 0.0492 & 0.1302 \\
\hline
\end{tabular}


TABLE 5B Variance inflation factors (VIF) of the single-scale model

\begin{tabular}{ll} 
Predictors & VIF \\
\hline Patch structure & 1.37 \\
\hline Fleshy fruit availability & 1.58 \\
\hline Preferred THV & 1.49 \\
\hline Hunting signs & 1.02 \\
\hline Hunting pressure & 1.23 \\
Village influence & 1.31 \\
\hline Nesting site fidelity & 1.14 \\
\hline
\end{tabular}

2005; Quinn \& Keough, 2002). As our data showed some potentially influential cases, we reran the model on a subset of our data $(N=261$ of the 284 transect segments). We checked model estimates and compared them with the estimates of the full model (Table 5C. As we found very little variation, we report results for the model based on the full dataset. We then checked dfbeta (Field, 2005) to see if some particularly transect segments might have heavily influenced the estimates. Values for the 'hunting pressure' and 'hunting signs' predictors indicated some problems (Table 5D). For each predictor, we checked the transect segments which induced changes of more than $10 \%$ in any part of the estimate ( $N=95$ for 'hunting signs', $N=43$ for 'hunting pressure'). For 'hunting signs', almost all segments with hunting signs present (34 out of 40 segments) showed dfbeta issues. We decided to run the model without this predictor to check if it influenced the estimates of the other predictors. As the estimates were similar (Table 5C), we kept the 'hunting sign' predictor. For 'hunting pressure', we ran a model with a subset of data excluding segments with dfbeta issues. Again, the estimates were similar in
TABLE 5D Dfbeta (absolute maximum value) of predictor estimates

\begin{tabular}{lll}
\hline & Estimates & $\begin{array}{l}\text { Dfbeta (maximum } \\
\text { absolute value) }\end{array}$ \\
\hline (Intercept) & $-1.956^{* * *}$ & 0.0459 \\
\hline Patch structure & $1.075^{* * *}$ & 0.0533 \\
\hline Fleshy fruit availability & 0.454 & 0.0774 \\
\hline Preferred THV & $0.914^{* *}$ & 0.0509 \\
\hline $\begin{array}{l}\text { Interaction of fleshy fruit } \\
\text { availability and preferred }\end{array}$ & $-0.914^{* * *}$ & 0.0623 \\
\hline THV & & \\
\hline Hunting signs & 0.038 & $0.0644^{\mathrm{a}}$ \\
\hline Hunting pressure & 0.029 & $0.0606^{\mathrm{a}}$ \\
\hline $\begin{array}{l}\text { Village influence } \\
\text { Nesting site fidelity }\end{array}$ & 0.306 & 0.0491 \\
\hline Autocorrelation term & $0.570^{* *}$ & 0.0507 \\
\hline
\end{tabular}

${ }^{* * *}$ Indicates predictors with a $p<0.0001,{ }^{* *}$ a $p<0.001,{ }^{*}$ a $p<0.05$.

${ }^{a}$ These two values might present some potential issues.

comparison with the first model (Table 5C). We thus decided to base our inference on the entire dataset.

\section{Scale range models}

In order to check if the model assumptions were fulfilled for the spatial scale range models, we looked at Pearson correlations between predictor values of the single-scale model and their corresponding values extracted on each discrete buffer for the scale range models (Table 5E). As Pearson correlations were mainly higher than 0.70 (with some values decreasing to 0.42 outside the suitable spatial scale range), we assumed that the goodness of fit of the scale range models would be equivalent to the single-scale model.

TABLE 5C Comparison between the estimates of the single-scale model and estimates of different reduced models made in order to investigate potential model assumptions issues

\begin{tabular}{|c|c|c|c|c|}
\hline & $\begin{array}{l}\text { Estimates (single } \\
\text { scale model) }\end{array}$ & $\begin{array}{l}\text { Estimates (subset after } \\
\text { leverage) }^{\text {b }}\end{array}$ & $\begin{array}{l}\text { Estimates }(\mathrm{w} / \mathrm{o} \\
\text { hunting signs) }\end{array}$ & $\begin{array}{l}\text { Estimates (subset after } \\
\text { dfbeta issues) }^{\text {d }}\end{array}$ \\
\hline (Intercept) & $-1.956^{* * *}$ & $-2.191^{* * *}$ & $-1.952^{* * *}$ & $-2.608^{* * *}$ \\
\hline Fleshy fruit availability & 0.454 & 0.524 & 0.462 & 0.586 \\
\hline Preferred THV & $0.915^{* *}$ & $1.058^{* *}$ & $0.916^{* *}$ & $1.164^{* *}$ \\
\hline Hunting signs & 0.037 & 0.257 & - & 0.288 \\
\hline Hunting pressure & 0.03 & 0.167 & 0.035 & -0.247 \\
\hline Village influence & 0.306 & 0.506 & 0.3 & 0.206 \\
\hline Nesting site fidelity & $0.570^{* *}$ & 0.442 & $0.570^{* *}$ & $0.698^{* * *}$ \\
\hline
\end{tabular}

${ }^{* * *}$ Indicates predictors with a $p<0.0001,{ }^{* *}$ a $p<0.001,{ }^{*}$ a $p<0.05$.

${ }^{a}$ Estimates for the single-scale model.

${ }^{b}$ Estimates for the model using a subset of the data after having removed transect segments that were associated with larger leverage values.

'Estimates for the model without the predictor 'hunting signs' (as almost all transect segments with presence of hunting signs revealed potential issues based on dfbetas values).

${ }^{d}$ Estimates for the model using a subset of data after removing transect segments for which dfbetas values revealed issues for the predictor 'hunting pressure'. 
TABLE 5E Pearson correlations between predictor variables of the single-scale model and those extracted for each discrete buffer in the spatial scale range models

\begin{tabular}{|c|c|c|c|c|c|c|}
\hline \multirow[b]{2}{*}{ Buffer radius $(\mathrm{m})$} & \multicolumn{3}{|c|}{ Extraction of the weighted mean value } & \multicolumn{3}{|c|}{ Extraction of the arithmetic mean value } \\
\hline & Patch structure & Fleshy fruit availability & Preferred THV & Patch structure & Fleshy fruit availability & Preferred THV \\
\hline 30 & - & 0.98 & 0.97 & - & 0.98 & 0.98 \\
\hline 120 & - & 0.99 & 0.99 & - & 1 & 1 \\
\hline 210 & 0.53 & 1 & 1 & 0.6 & 0.99 & 0.92 \\
\hline 450 & - & 0.98 & - & 0.7 & 0.88 & - \\
\hline 600 & 0.67 & 0.95 & 0.92 & 0.74 & 0.83 & 0.74 \\
\hline 750 & 0.71 & - & - & - & - & - \\
\hline 900 & 0.74 & - & - & - & - & - \\
\hline 1800 & 0.88 & - & - & - & - & - \\
\hline 1950 & 0.9 & - & - & 0.98 & - & - \\
\hline 2100 & 0.91 & - & - & - & - & - \\
\hline 2400 & 0.94 & 0.74 & 0.59 & 1 & 0.65 & 0.46 \\
\hline 2700 & 0.95 & - & - & 1 & - & - \\
\hline
\end{tabular}

Appendix 6: Spatial Scale Range Models with Non-Distance

Weighted
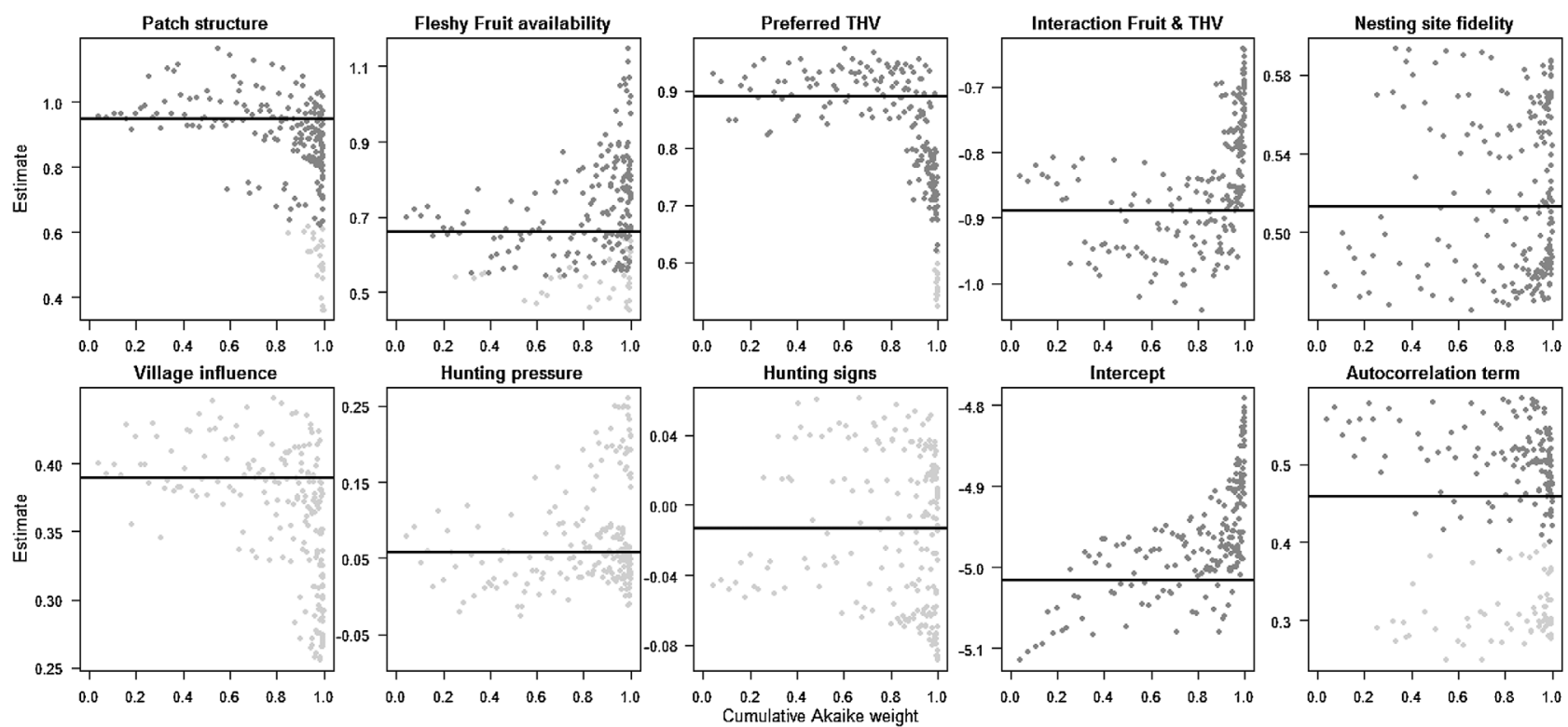

FIGURE 6.1 Variation in in the influence of parameters: scale range models with non-distance weighted predictor-value extraction 
Appendix 7: Variation in Parameter Influence within All

Implemented Models
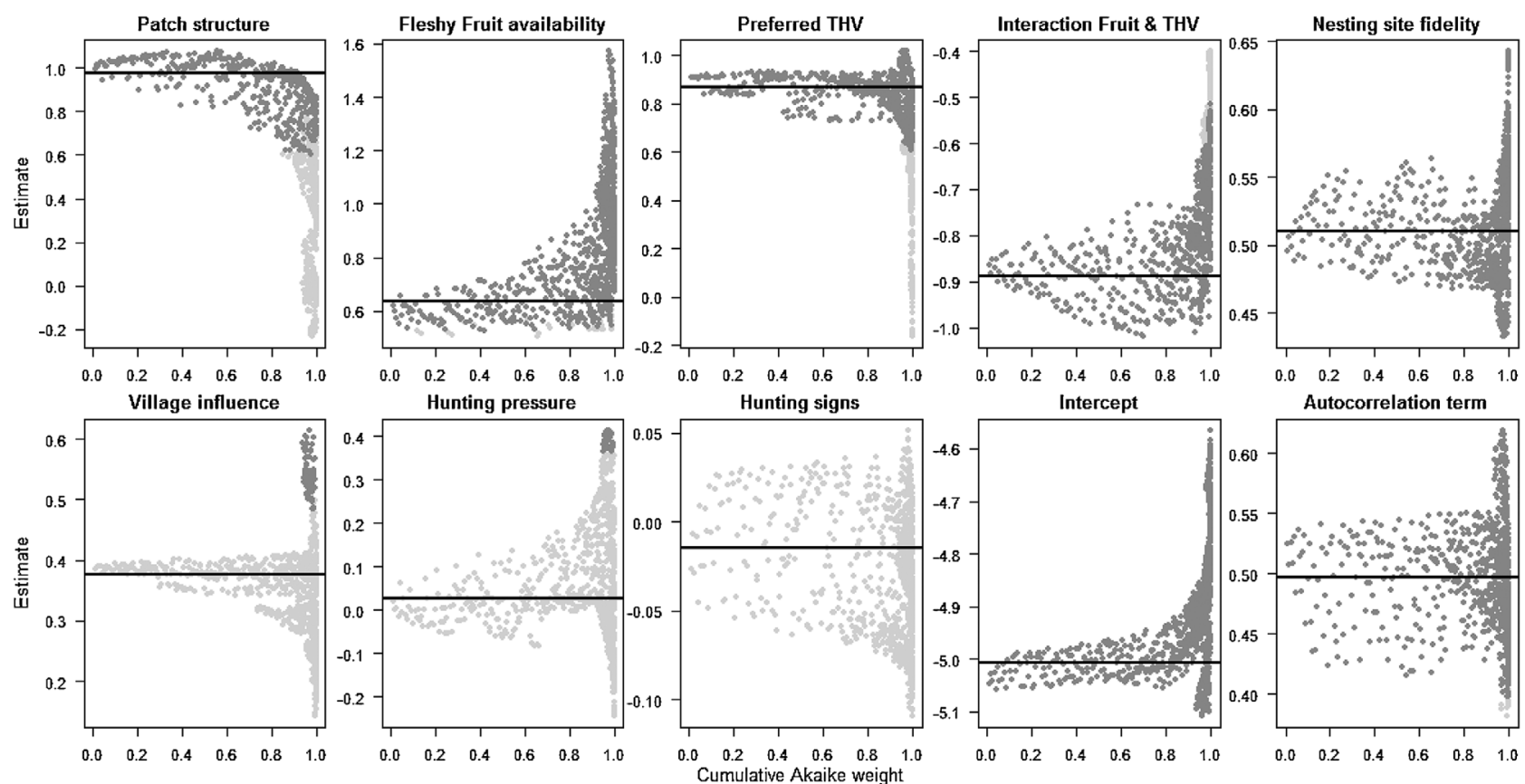

FIGURE 7.1 Variation in parameter influence within all implemented models. Parameter estimates are presented according to the cumulative Akaike weight of the models ( $X$-axis) within the suitable spatial scale ranges of the three environmental predictors. The colour of the points indicates the significance of the parameters (black points represent significant parameters, $p<0.05$; grey points represent non-significant ones). The horizontal lines indicate the global mean estimates of the parameters 